\title{
Using Micro- and Nanofibrillated Cellulose as a Means to Reduce Weight of Paper Products: A Review
}

Franklin Zambrano, ${ }^{\mathrm{a}}$ Heather Starkey, ${ }^{\mathrm{a}}$ Yuhan Wang, ${ }^{\mathrm{a}}$ Camilla Abbati de Assis, ${ }^{\mathrm{a}}$ Richard Venditti, ${ }^{a}$ Lokendra Pal, ${ }^{a}$ Hasan Jameel, ${ }^{a}$ Martin A. Hubbe, ${ }^{a}$ Orlando J. Rojas, and Ronalds Gonzalez ${ }^{\mathrm{a}, *}$

\begin{abstract}
Based on publications related to the use of micro- and nanofibrillated cellulose (MNFC) in papermaking applications, three sets of parameters (intrinsic and extrinsic variables, furnish composition, and degree of dispersion) were proposed. This holistic approach intends to facilitate understanding and manipulation of the main factors describing the colloidal behavior in systems comprising of MNFC, pulp fibers, and additives, which directly impact paper product performance. A preliminary techno-economic assessment showed that cost reductions driven by the addition of MNFC in paper furnishes could be as high as USD 149 per ton of fiber (up to $20 \%$ fiber reduction without adverse effects on paper's strength) depending on the cost of papermaking fibers. It was also determined that better performance in terms of strength development associated with a higher degree of MNFC fibrillation offset its high manufacturing cost. However, there is a limit from which additional fibrillation does not seem to contribute to further strength gains that can justify the increasing production cost. Further research is needed regarding raw materials, degree of fibrillation, and combination with polyelectrolytes to further explore the potential of MNFC for the reduction of weight of paper products.
\end{abstract}

Keywords: Micro- and nanofibrillated cellulose (MNFC); Microfibrillated cellulose (MFC); Nanofibrillated cellulose (NFC); CNF; CMF; Tensile strength; Fiber reduction; Light-weight paper; Paper products; Retention aids; Cellulose fibers

Contact information: a: Department of Forest Biomaterials, Science and Engineering, P. O. Box 8005, North Carolina State University, Raleigh, NC 27695-8005 USA; b: Department of Bioproducts and Biosystems, School of Chemical Engineering, Aalto University, Espoo, 02150 Finland;

*Corresponding author: rwgonzal@ncsu.edu

\section{INTRODUCTION}

The global trend toward digitalization has caused a decline in the consumption and production of printing and writing paper grades. Such reduction has been reported to be approximately $15 \%$ across the last 10 years with a forecasted drop of $4 \%$ over the next five years. Recycled fibers, more specifically "mixed office waste (MOW)" and "white office ledger (WOL)", are the most used recycled fibers in the hygiene tissue industry (De Assis et al. 2018b). As digitalization continues to force a reduction in production of printing and writing papers, less MOW and WOL are available to produce recycled paper grades. This disruption in fiber supply has resulted in huge increases and fluctuations in fiber prices (Fig. 1).

Not only has the availability of fiber been decreasing, but the quality of the fiber that is available has been continuously decreasing as well, resulting in weaker paper. Decrease in paper strength is a major concern since quality standards are rising (RISI

Zambrano et al. (2020). "Nanocellulose \& grammage," BioResources 15(2), 4553-4590. 4553 
2017). Papermakers tend to redress this situation by using expensive fibers that are better quality than the low-cost alternatives. Some even resort to the use of synthetic additives, which results in increased costs per ton of finished product. To meet market expectations regarding paper strength, mechanical refining of recycled and virgin fibers is a common practice in the industry (Hubbe 2007a). However, in the case of tissue products, even though refining helps to develop fiber and web strength, at the same time it makes the sheet denser and more rigid, which negatively affects water absorbency, bulk, and softness of the tissue sheet, which are key properties of the final product (Kullander et al. 2012).

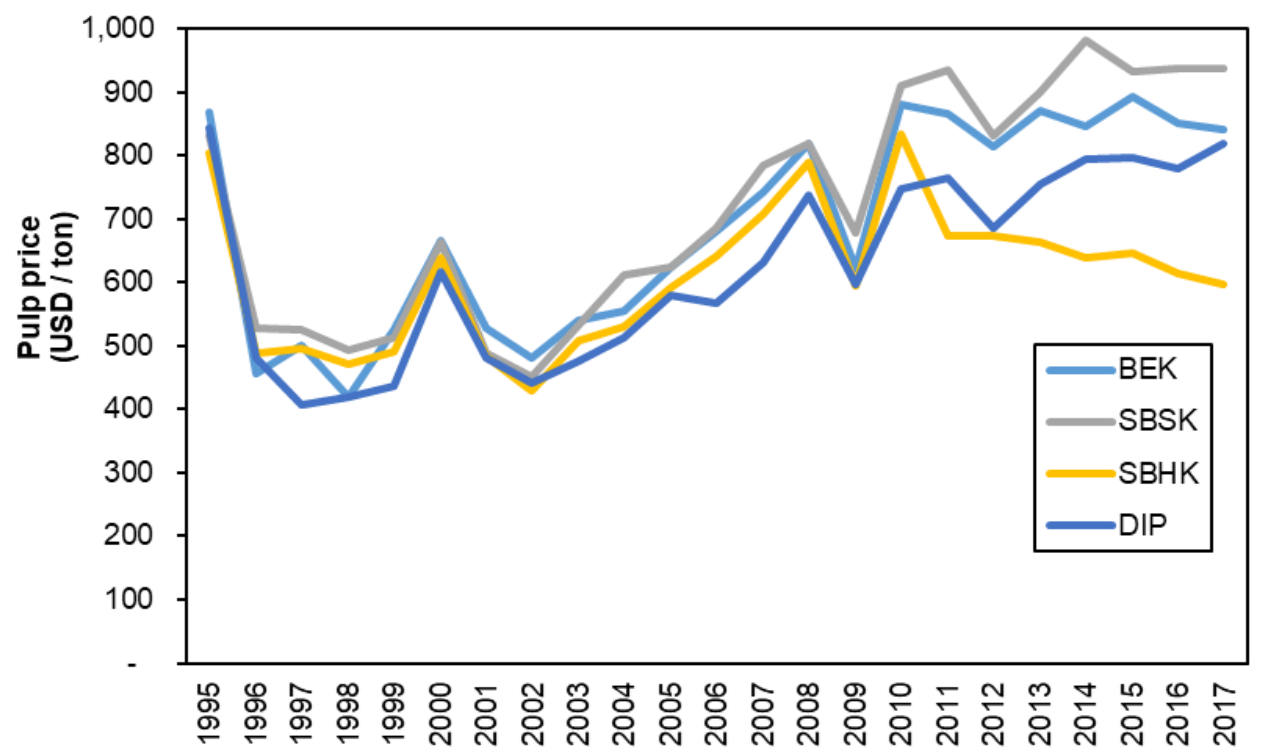

Fig. 1. Historic fiber cost data for major grades of recycled and virgin fibers: BEK: bleached Eucalyptus kraft; SBSK: southern bleached softwood kraft; SBHK: southern bleached hardwood kraft; DIP: deinked pulp; graph generated with data collected from Fastmarkets RISI (2017)

There is a pressing need to develop new technologies to face current and future market challenges related to fiber supply, quality, and cost while meeting changes in consumption patterns. Micro- and nanofibrillated (MNFC) has emerged as a promising candidate to generate either high-value applications or low-cost alternatives. Thus far, available reports have been focused on the improvement in tensile strength by addition of MNFC in paper furnishes (Eriksen et al. 2008; Taipale et al. 2010; He et al. 2017). This might be mainly beneficial for poor quality furnishes composed of recycled fibers, where strength properties of such fibers can be insufficient to meet specifications of a paper grade. However, for paper products where strength is not an issue, consumers are not willing to pay a premium for a product that has a superior strength (De Assis et al. 2018a). Therefore, in such cases it makes more sense to consider the gains in strength obtained by MNFC to reduce the fiber content of the paper product instead of merely developing excess strength. This strategy could potentially allow the production of a lighter-weight version of commercially available papers with properties that are consistent to those available in the market but at a lower manufacturing cost. Moreover, a more rapid adoption of the nanomaterial by the industry can be stimulated given the possible overall economic gain offsetting the high perceived cost of MNFC. 
Acknowledging this opportunity, the main goal of this work is to review what is known about factors that affect the ability of highly fibrillated cellulosic materials, such as MNFC, to provide strength and possibly to allow for reductions in the basis weight of various paper products. To accomplish that goal, this review will begin by examining background information concerning nanocellulosic materials and their application in papermaking. To this end, a holistic approach will be used to provide readers with an effective means to rationalize the main variables affecting the performance of MNFC in paper furnishes. Identification of knowledge gaps as potential areas for further research will be emphasized. When considering the factors affecting paper strength - with attention to how the usage of MNFC can augment paper strength - it will be argued that some of the key challenges in research, up to this point, have involved uncertainties concerning the retention of MNFC. Another key challenge, especially when attempting to compare results of different studies, is that chemical aids intended to retain MNFC in the paper may also affect fiber network formation, and therefore the strength of the sheet. After reviewing these factors, two case studies will be considered to highlight economic considerations that may be important relative to commercialization of MNFC as an additive for fiber reduction in papermaking.

\section{DIGGING INTO THE CELLULOSE STRUCTURE: NANOCELLULOSE}

To enable a better understanding of the potential roles of MNFC as an additive in paper grade applications, this section provides background about MNFC, including its types, some aspects of its chemistry and morphology, and production.

\section{Cellulose and Nanocellulose}

Cellulose is one of the most important renewable natural biopolymers and is almost inexhaustible as a raw material (Siró and Plackett 2010; González et al. 2014). Wood is the major source of cellulose, but other important natural sources where cellulose is likewise widely distributed are plant fibers (cotton, hemp, flax, etc.), marine animals (tunicates), and to a lesser degree algae, fungi, invertebrates, and bacteria (Lavoine et al. 2012). Irrespective of its source, cellulose is a high molecular weight homopolymer whose repeating unit is glucose (French 2017). Cellulose consists of a linear homopolysaccharide composed of $\beta$-D-glucopyranose units linked together by $\beta$-1-4-linkages (Habibi et al. 2010).

In nature, cellulose is found as assemblies of individual cellulose chains that are formed into fibers. This structure is the result of a hierarchical organization (Fig. 2). Approximately 36 individual cellulose molecular chains are biologically assembled within biomass into larger units known as elementary fibrils. These elementary fibrils, which are commonly considered as the smallest morphological units in the fibers, are packed into a bundle of larger units called cellulose microfibrils; these are in turn assembled to constitute the original cellulosic fiber (Habibi et al. 2010). In this configuration, each microfibril can be seen as a flexible hair strand made of crystalline cellulose regions linked along the microfibril axis by amorphous domains. The diameter of elementary fibrils is approximately $3 \mathrm{~nm}$ (Isogai 2013), whereas cellulose microfibrils have diameters ranging between 20 and $50 \mathrm{~nm}$ (Lavoine et al. 2012). Cellulose particles that exhibit at least one dimension in the nanometer range (1 to $100 \mathrm{~nm}$ ) are known as nanocellulose (Abdul Khalil et al. 2014). 


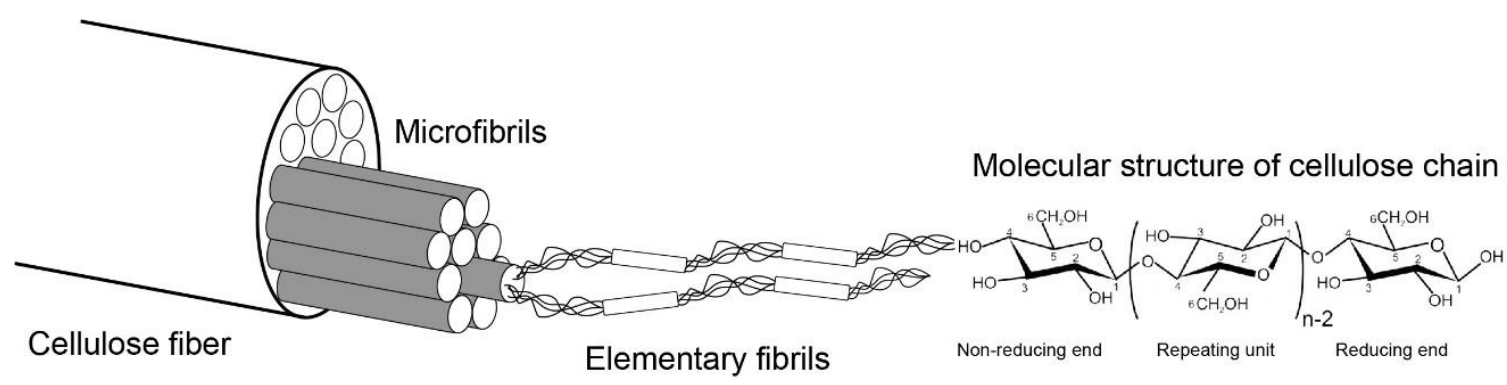

Fig. 2. Hierarchical organization of cellulose fiber showing molecular structure of cellulose polymer; Figure reinterpreted from Lavoine et al. 2012

\section{Types of Nanocellulose}

The manufacturing conditions used to convert macro-scale cellulose into its nanoscale form have a critical influence on the dimensions, composition, and properties of the resulting product. According to the type of treatment applied, two main classes of nanocellulose are distinguished: (i) cellulose nanocrystals (CNC) or cellulose nanowhiskers, which are obtained by acid treatment, and (ii) $\mathrm{CNF}$, also known as nanofibrillated cellulose (NFC), microfibrillated cellulose (MFC), or cellulose nanofibril, which are mainly produced by mechanical disintegration (Nechyporchuk et al. 2014). Table 2 summarizes the different nomenclatures found in literature to refer to cellulose nanostructures, as well as typical dimensions and raw materials used for their manufacture. The third type of nanocellulose formed by aerobic bacteria is discussed elsewhere (Nakagaito et al. 2005; Klemm et al. 2011; Ilyas et al. 2018).

Table 1. Family of Cellulose Nanostructures (Adapted from Siró and Plackett 2010; Klemm et al. 2011; llyas et al. 2018)

\begin{tabular}{|c|c|c|c|}
\hline $\begin{array}{c}\text { Type of } \\
\text { Nanocellulose }\end{array}$ & Synonyms & Average Size & Typical Sources \\
\hline $\mathrm{CNC}$ & $\begin{array}{c}\text { Nanocrystalline } \\
\text { cellulose (NCC), } \\
\text { whiskers, rod-like } \\
\text { cellulose microcrystals, } \\
\text { bacterial nanocellulose } \\
\text { (BNC, synthesized by } \\
\text { using bacterial method) }\end{array}$ & $\begin{array}{l}\text { Diameter: } 5 \text { to } 70 \mathrm{~nm} \\
\text { Length: } 100 \text { to } 250 \\
\text { nm (from plants); } 100 \\
\text { nm to several } \\
\text { micrometers (from } \\
\text { tunicates, algae, } \\
\text { bacteria) }\end{array}$ & $\begin{array}{l}\text { Wood, cotton, } \\
\text { hemp, flax, wheat } \\
\text { straw, rice straw, } \\
\text { mulberry bark, } \\
\text { ramie, MCC, Avicel, } \\
\text { tunicin, algae, } \\
\text { bacteria, etc. }\end{array}$ \\
\hline CNF & $\begin{array}{l}\text { NFC, MFC, nanofibril, } \\
\text { microfibril }\end{array}$ & $\begin{array}{l}\text { Diameter: } 6 \text { to } 50 \mathrm{~nm} \\
\text { Length: several } \\
\text { micrometers }\end{array}$ & $\begin{array}{l}\text { Wood, sugar beet, } \\
\text { potato, tuber, hemp, } \\
\text { flax, etc. }\end{array}$ \\
\hline
\end{tabular}

Cellulose nanocrystals consist of rod-like crystals produced through the acid hydrolysis of cellulose fibers (Jonoobi et al. 2015). The acid treatment degrades the amorphous regions of cellulose, leaving the crystalline regions intact (Lavoine et al. 2012). The morphology, dimensions, and degree of crystallinity highly depend on the source of cellulosic material used, as well as on the conditions applied for the nanocellulose production (Habibi et al. 2010). As a general trend, CNC particles exhibit a typical width of 2 to $20 \mathrm{~nm}$, with a length ranging between $100 \mathrm{~nm}$ and $250 \mathrm{~nm}$ when produced from cellulose fibers, and a crystallinity index that varies between 54 and $88 \%$ (Moon et al. 2011). CNC produced from tunicates can reach lengths of several micrometers but they are rarely used in practical systems. 
Cellulose nanofibrils consist of a bundle of stretched cellulose chain molecules moderately degraded and with a greatly expanded surface area (Klemm et al. 2011). Unlike $\mathrm{CNC}$, these nanofibrils are comprised of strongly entangled networks that contain both crystalline and amorphous domains. Depending on the production pathway, CNF has dimensions of 5 to $50 \mathrm{~nm}$ in width and a length of several micrometers. This range considers the blend of single elementary fibrils and their bundles. As a general estimation, if elementary fibrils have between 2- and 10-nm-thick fibrous cellulose structure, CNFs are composed of approximately 10 to 50 units of elementary fibrils (Siró and Plackett 2010; Lavoine et al. 2012).

It is worth noting that the many terminologies considered to describe these cellulosic nanomaterials have led to some misunderstanding. Consequently, several technical committees and organizations have initiated standards, e.g., ISO/TC6-TG1 (1947) and ISO/TC 229 (2005), TAPPI WI 3021 (2012), and CSA Z5100 (2014), for defining the different types of nanocellulose (Nechyporchuk et al. 2016). The irregularity inherent to the mechanical process used to produce cellulose nanofibrils makes standardization a challenging task, as the produced material may consist of a blend of different structures. Chinga-Carrasco (2011) concluded that microfibrillated cellulose obtained by homogenization might be composed of (1) nanofibrils, (2) fibrillary fines, (3) fiber fragments, and (4) fibers. For properly produced MFC materials, nanostructures represent the main component. Other authors claim that CNF can only be obtained from cellulose fibers pretreated using TEMPO-mediated oxidation (Isogai 2013). To avoid possible ambiguities, the authors of this review prefer the term MNFC for considering it broad enough to include the various structures derived from the smallest morphological units of the cellulosic fibers that can have sizes ranging between micrometers and nanometers. However, any reference to external study will consider the terminology used by the corresponding authors.

\section{Production Pathways}

The most common pathway to produce MNFC is through delamination of wood pulp via an intensive mechanical process after chemical or enzymatic treatment (Klemm et al. 2011). According to the nature of the raw material and degree of processing desired, the feedstock can be submitted to chemical treatment before mechanical processing, e.g., TEMPO-oxidation or carboxymethylation, to produce MNFC at higher fibrillation and lower energy consumption (Islam et al. 2014). Once the purified cellulose pulp is prepared, several methods can be applied for its conversion into highly purified nanofibrils. Typical mechanical procedures used are refining, homogenization (homogenizers and microfluidizers), and grinding. These technologies, which are suitable for upscaling, have been demonstrated to be highly efficient tools used in delamination of the fiber cell wall and subsequent MNFC isolation, despite requiring high amounts of energy (Nechyporchuk et al. 2016).

Depending on the disintegration process, the cellulosic raw material and its preand post-treatment (if applied), MNFC with different fibril dimensions and amount of residual microscopic fiber fragments are obtained. Other important changes in features, such as surface chemistry, crystallinity, and degree of polymerization are also influenced by those factors (Abdul Khalil and Bhat 2012; Nechyporchuk et al. 2014). Therefore, the production pathway should be selected based on a techno-economic assessment and the desired features of the final product (Spence et al. 2010a,b, 2011). Figure 3 shows 
conventional strategies and other alternative paths available for each stage of the manufacturing process of MNFC.

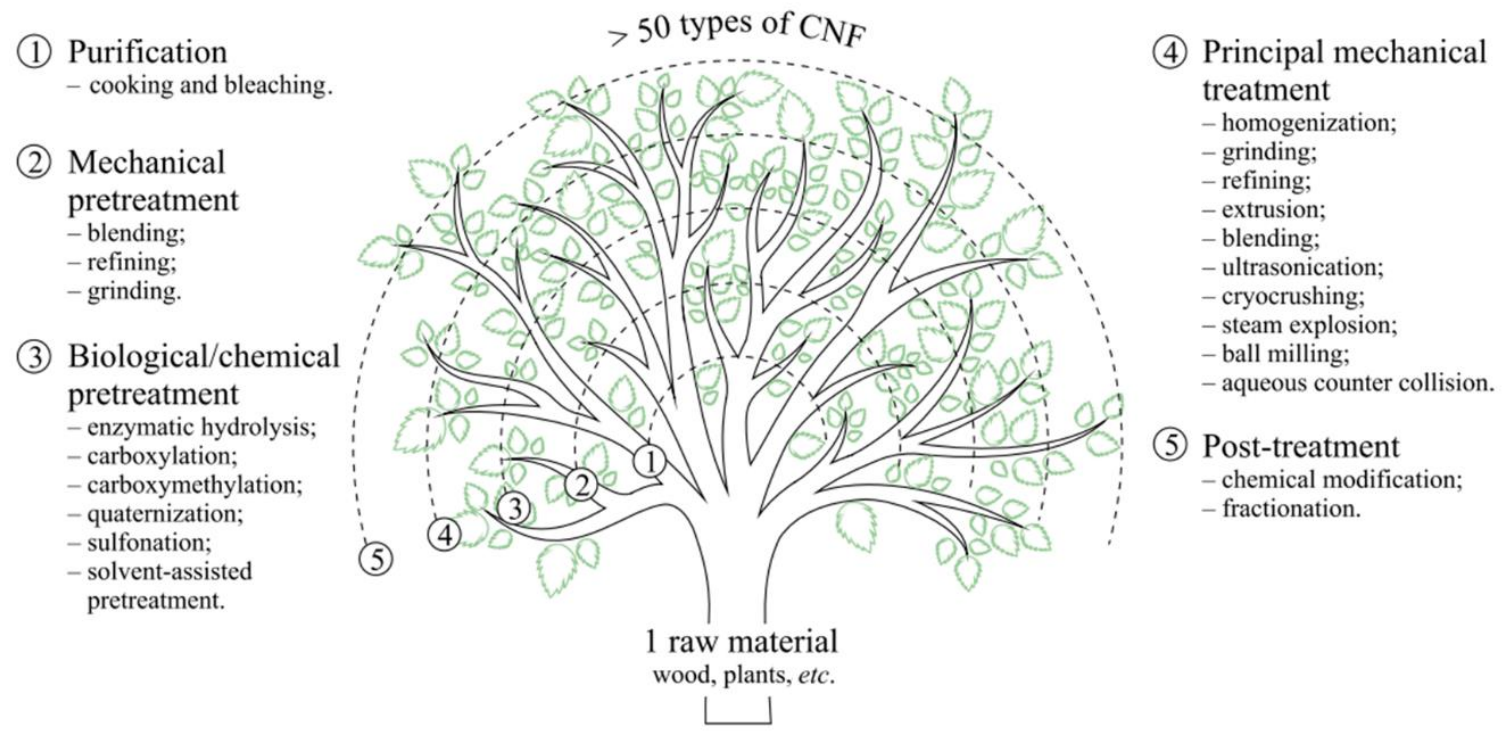

Fig. 3. MNFC production tree showing general stages and available processing operations (Copyright Elsevier; Nechyporchuk et al. 2016)

From an operational point of view, direct treatment of dry cellulose pulp using mechanical methods alone leads to segments of MNFC having a low degree of polymerization, crystallinity, and aspect ratio, which is a consequence of fiber shredding, rather than elementary fibril delamination. These features can result in poor performance of MNFC when used to improve the mechanical properties of materials. To overcome this situation, production of MNFC can be completed in aqueous dispersions of cellulose with a low concentration $(<5 \mathrm{wt} \%)$, which eases the delamination of nanofibrils due to a decrease in the interfibrillar hydrogen bonding energy. At the same time, these operating conditions minimize the potential cutting of fibrils (Nechyporchuk et al. 2016). It is important to note that the high-water absorption capacity exhibited by cellulose nanostructures produces highly viscous dispersions even at low concentrations. Such dispersions can be thought of to have a gel-like structure, which can be difficult to process. For this reason, the dependence of the viscosity on the MNFC concentration is a key factor to consider when evaluating practical yields.

\section{STATE-OF-THE-ART APPLICATIONS FOR THE USE OF MICRO- AND NANOFIBRILLATED CELLULOSE IN PAPERMAKING}

Before considering evidence that MNFC can help to address some of the challenges introduced above, this section provides a patent perspective regarding the evolution of the applications for MNFC and includes review papers that have discussed the use of MNFC as a papermaking additive.

The study of nanomaterials represents an emerging field that is finding an increasing number of applications in daily consumer commodities (Wijnhoven et al. 2009). Micro- and nanoscale fibrillated cellulose can be introduced to improve the performance 
of paper products, one of the most promising areas where these bio-nanomaterials can find a commercial niche in a short term (Osong et al. 2016). This arises as a result of nanocellulose's set of features, such as high abundance, high stiffness, low density, and environmentally friendly nature, all of which can serve as a starting point to provide a final product with exceptional characteristics (Siró and Plackett 2010; Dufresne 2013).

Increasing interest in nanocellulose technology is reflected in the large number of patents available on the topic. Charreau et al. (2012) provided a comprehensive review on the number of patents published every year on cellulose nanoparticles, which included cellulose nanocrystals, microfibrillated cellulose, and bacterial cellulose. Numerous patents regarding micro- and nanofibrillated cellulose have been issued since 2012. A selection of patents specifically looking at MNFC applications in papermaking is presented in Table 1 to highlight specific areas of growing interest: coated paper and tissue and towel. For each publication number, the title, current assignee, status, publication year, and application field are indicated. Table 1 shows a trend between the application field and the publication year for the group of patents. Coated paper applications correspond to early patents, published between 1994 and 2012, dealing with methods for preparing aqueous suspensions comprising MNFC to be used as coating layers in different fiber-based substrates. A brief patent overview published by Brodin et al. (2014) elaborates on the use of MNFC in the coating of paper.

Table 1. Patents Issued on Micro- and Nanofibrillated Applications in Papermaking

\begin{tabular}{|c|c|c|c|c|c|}
\hline $\begin{array}{l}\text { Application } \\
\text { Field }\end{array}$ & $\begin{array}{c}\text { Publication } \\
\text { Number }\end{array}$ & Title of Patent & $\begin{array}{c}\text { Current } \\
\text { Assignee }\end{array}$ & Status & Year \\
\hline \multirow{5}{*}{$\begin{array}{l}\text { Hygiene } \\
\text { tissues, } \\
\text { towels, } \\
\text { napkins and } \\
\text { absorbent } \\
\text { products }\end{array}$} & EP2191066B1 & $\begin{array}{l}\text { Absorbent sheet } \\
\text { incorporating regenerated } \\
\text { cellulose microfiber }\end{array}$ & $\begin{array}{l}\text { Georgia-Pacific } \\
\text { Consumer } \\
\text { Products LP }\end{array}$ & Granted & 2016 \\
\hline & US9518364B2 & $\begin{array}{l}\text { Wet-laid sheet material of } \\
\text { a microfibrillated material } \\
\text { composition }\end{array}$ & Stora Enso Oyj & Granted & 2016 \\
\hline & US8216425B2 & $\begin{array}{l}\text { Absorbent sheet having } \\
\text { regenerated cellulose } \\
\text { microfiber network }\end{array}$ & $\begin{array}{l}\text { Georgia-Pacific } \\
\text { Consumer } \\
\text { Products LP }\end{array}$ & Granted & 2012 \\
\hline & US8177938B2 & $\begin{array}{l}\text { Method of making } \\
\text { regenerated cellulose } \\
\text { microfibers and } \\
\text { absorbent products } \\
\text { incorporating same }\end{array}$ & $\begin{array}{l}\text { Georgia-Pacific } \\
\text { Consumer } \\
\text { Products LP }\end{array}$ & Granted & 2012 \\
\hline & $\begin{array}{c}\text { US20020162635 } \\
\text { A1 }\end{array}$ & $\begin{array}{l}\text { Softer and higher } \\
\text { strength paper products } \\
\text { and methods of making } \\
\text { such products }\end{array}$ & $\begin{array}{c}\text { Research } \\
\text { Foundation of } \\
\text { State University } \\
\text { of New York }\end{array}$ & Application & 2002 \\
\hline \multirow{2}{*}{$\begin{array}{l}\text { Different } \\
\text { paper and } \\
\text { paperboard } \\
\text { products }\end{array}$} & US8945345B2 & $\begin{array}{l}\text { Method for producing } \\
\text { furnish, furnish and paper }\end{array}$ & $\begin{array}{l}\text { UPM- } \\
\text { Kymmene Oy }\end{array}$ & Granted & 2015 \\
\hline & EP2014828B1 & $\begin{array}{c}\text { Cellulose-based fibrous } \\
\text { materials }\end{array}$ & $\begin{array}{l}\text { Nippon Paper } \\
\text { Industries Co., } \\
\text { Ltd.; Jujo Paper } \\
\text { Co., Ltd. } \\
\end{array}$ & Granted & 2014 \\
\hline
\end{tabular}




\begin{tabular}{|c|c|c|c|c|c|}
\hline & $\begin{array}{c}\text { WO2013072550 } \\
\text { A3 }\end{array}$ & $\begin{array}{l}\text { A paper product and a } \\
\text { method and a system for } \\
\text { manufacturing a paper } \\
\text { product }\end{array}$ & $\begin{array}{c}\text { UPM- } \\
\text { Kymmene } \\
\text { Corporation }\end{array}$ & Application & 2013 \\
\hline & US8377563B2 & $\begin{array}{l}\text { Additive for papermaking } \\
\text { and paper containing the } \\
\text { same }\end{array}$ & $\begin{array}{l}\text { Nippon Paper } \\
\text { Industries Co., } \\
\text { Ltd.; Jujo Paper } \\
\text { Co., Ltd. } \\
\end{array}$ & Granted & 2013 \\
\hline & $\begin{array}{c}\text { WO2012039668 } \\
\text { A1 }\end{array}$ & $\begin{array}{l}\text { A paper or paperboard } \\
\text { product and a process for } \\
\text { production of a paper or } \\
\text { paperboard product }\end{array}$ & Stora Enso Oyj & Application & 2012 \\
\hline & $\begin{array}{c}\text { WO2010131016 } \\
\text { A3 }\end{array}$ & Paper filler composition & $\begin{array}{l}\text { Imerys } \\
\text { Minerals } \\
\text { Limited }\end{array}$ & Application & 2011 \\
\hline & EP0403849B1 & $\begin{array}{l}\text { High opacity paper } \\
\text { containing expanded fiber } \\
\text { and mineral pigment }\end{array}$ & $\begin{array}{l}\text { Weyerhaeuser } \\
\text { Co. }\end{array}$ & Granted & 1994 \\
\hline \multirow{9}{*}{$\begin{array}{l}\text { Coated paper } \\
\text { or board } \\
\text { products, } \\
\text { filled papers, } \\
\text { dyed papers }\end{array}$} & $\begin{array}{l}\text { WO2013061266 } \\
\text { A1 }\end{array}$ & $\begin{array}{l}\text { Process for producing a } \\
\text { dispersion comprising } \\
\text { nanoparticles and a } \\
\text { dispersion produced } \\
\text { according to the process }\end{array}$ & Stora Enso Oyj & Application & 2013 \\
\hline & $\begin{array}{l}\text { WO2012163711 } \\
\text { A1 }\end{array}$ & $\begin{array}{c}\text { Process for } \\
\text { manufacturing coated } \\
\text { substrates }\end{array}$ & $\begin{array}{c}\text { Omya } \\
\text { Development } \\
\mathrm{Ag}\end{array}$ & Application & 2012 \\
\hline & $\begin{array}{l}\text { WO2011056130 } \\
\text { A1 }\end{array}$ & $\begin{array}{l}\text { A coated substrate, a } \\
\text { process for production of } \\
\text { a coated substrate, a } \\
\text { package, and a } \\
\text { dispersion coating }\end{array}$ & Stora Enso Oyj & Application & 2011 \\
\hline & $\begin{array}{c}\text { WO2011147825 } \\
\text { A1 }\end{array}$ & $\begin{array}{l}\text { Cellulosic barrier } \\
\text { composition }\end{array}$ & $\begin{array}{c}\text { Akzo Nobel } \\
\text { Chemicals } \\
\text { International } \\
\text { B.V. }\end{array}$ & Application & 2011 \\
\hline & $\begin{array}{l}\text { WO2011005181 } \\
\text { A1 }\end{array}$ & $\begin{array}{c}\text { Barrier layer for a } \\
\text { packaging laminate and } \\
\text { packaging laminate } \\
\text { comprising such barrier } \\
\text { layer } \\
\end{array}$ & $\begin{array}{l}\text { Tetra Laval } \\
\text { Holdings and } \\
\text { Finance Sa }\end{array}$ & Application & 2011 \\
\hline & $\begin{array}{c}\text { WO2012066308 } \\
\text { A3 }\end{array}$ & Composition & $\begin{array}{c}\text { Imerys } \\
\text { Minerals } \\
\text { Limited } \\
\end{array}$ & Application & 2010 \\
\hline & $\begin{array}{l}\text { WO2009123560 } \\
\text { A1 }\end{array}$ & $\begin{array}{l}\text { Composition for coating } \\
\text { of printing paper }\end{array}$ & $\begin{array}{l}\text { Stfi-Packforsk } \\
\text { Ab }\end{array}$ & Application & 2009 \\
\hline & $\begin{array}{c}\text { WO2009020239 } \\
\text { A1 }\end{array}$ & Gas barrier material & $\begin{array}{c}\text { Kao } \\
\text { Corporation }\end{array}$ & Application & 2009 \\
\hline & $\begin{array}{l}\text { WO2007088974 } \\
\text { A1 }\end{array}$ & $\begin{array}{l}\text { Method of imparting } \\
\text { water repellency and oil } \\
\text { resistance with use of } \\
\text { cellulose nanofiber }\end{array}$ & $\begin{array}{c}\text { Kyushu } \\
\text { University, } \\
\text { National } \\
\text { University } \\
\text { Corporation }\end{array}$ & Application & 2007 \\
\hline
\end{tabular}




\begin{tabular}{|c|c|c|c|c|}
\hline US6214163B1 & $\begin{array}{l}\text { Super microfibrillated } \\
\text { cellulose, process for } \\
\text { producing the same, and } \\
\text { coated paper and tinted } \\
\text { paper using the same }\end{array}$ & $\begin{array}{l}\text { Tokushu Paper } \\
\text { Manufacturing } \\
\text { Co Ltd }\end{array}$ & Granted & 2001 \\
\hline US6214163B1 & $\begin{array}{l}\text { Super microfibrillated } \\
\text { cellulose, process for } \\
\text { producing the same, and } \\
\text { coated paper and tinted } \\
\text { paper using the same }\end{array}$ & $\begin{array}{l}\text { Tokushu Paper } \\
\text { Manufacturing } \\
\text { Co., Ltd. }\end{array}$ & Granted & 2001 \\
\hline JPH08284090A & $\begin{array}{c}\text { Ultrafine fibrillated } \\
\text { cellulose and its } \\
\text { production, production of } \\
\text { coated paper using the } \\
\text { ultrafine fibrillated } \\
\text { cellulose and production } \\
\text { of dyed paper }\end{array}$ & $\begin{array}{l}\text { Tokushu Paper } \\
\text { Mfg Co., Ltd. }\end{array}$ & Granted & 1999 \\
\hline JP2967804B2 & $\begin{array}{l}\text { Manufacturing method of } \\
\text { preparation and dyed } \\
\text { paper for coated paper } \\
\text { using ultrasonic } \\
\text { microfibrillated cellulose } \\
\text { and a method for } \\
\text { manufacturing the same, } \\
\text { an super microfibrillated } \\
\text { cellulose }\end{array}$ & $\begin{array}{l}\text { Tokushu Paper } \\
\text { Mfg Co., Ltd. }\end{array}$ & Granted & 1999 \\
\hline
\end{tabular}

Beginning in 2012, the application of MNFC expanded into broader categories, such as consumer products, more specifically tissue and towel grades. Sumnicht, and Sumnicht and Kokko from Consumer Products LP at Georgia-Pacific, submitted several patent applications on the hygiene consumer segment. The first two patents related to a method of making cellulose microfibers by splitting larger fibers of regenerated cellulose in high yield using low-intensity refining and incorporating such microfibers into absorbent sheets to provide strength, softness, bulk, and absorbency to tissue, towel, and personal care products (Sumnicht 2012; Sumnicht and Kokko 2012). A third patent provided more insights into the benefits that can be obtained by using microfibers. This latter invention related to an absorbent sheet made from papermaking fibers (e.g., softwood and hardwood cellulosic pulps) including regenerated cellulose microfibers. When comparing an equivalent sheet prepared without fibrillated cellulose microfiber, the resulting product was claimed to have higher absorbency $(+15 \%)$, wet tensile $(+40 \%)$, and a specific bulk $(+5 \%)$, making it an ideal candidate for applications in tissue papers (Sumnicht and Miller 2016). Goto et al. (2014) at Nippon Paper Group, Inc. filed a patent on fibrous materials with an assembly of microfibrils with a width of $3 \mu \mathrm{m}$ or more for obtaining sheets with low density and high surface quality in addition to high strength. The product of the invention was claimed for use in different paper grades, including facial tissue, toilet tissue, and paper towels (Goto et al. 2014). A recent patent filed by Stora Enso relates to a wet-laid sheet of a microfibrillated material composition intended for hygiene tissue applications (Heiskanen et al. 2016).

As pointed out by Charreau et al. (2012), and based on this brief patent review, worldwide corporations owning most of the patents have kept a consistent focus for the last five years, namely, finding high-value applications for MNFC to push value creation. 
Within this segment, MNFC is meant to improve water absorbency and tensile strength without affecting other key properties of interest in consumer products such as softness and bulkiness.

In academia, numerous authors have published recent reviews dealing with the use of MNFC as an additive in papermaking. A review was presented by Brodin et al. (2014), who discussed different strategies for incorporating cellulose nanofibrils (CNF) in pulp furnishes and results regarding drainage and paper properties that included density, permeability, strength, and light scattering coefficient. Osong et al. (2016) discussed the critical variables to consider before adding MNFC to pulp furnishes, i.e., production pathways, energy consumption, chemical and enzymatic pre-treatments, and characterization techniques. Meanwhile, Boufi et al. (2016) published a review that highlighted the progress in the field of cellulose nanofibers in papermaking applications and analyzed the effect of CNF according to the type of papermaking furnish.

\section{MICRO- AND NANOFIBRILLATED CELLULOSE AS A PAPER STRENGTH ADDITIVE IN PAPERMAKING APPLICATIONS}

Micro- and nanofibrillated cellulose products have been shown to be highperformance strength additives in paper and paperboard products (Eriksen et al. 2008; Taipale et al. 2010; He et al. 2017; Kasmani et al. 2019; Konstantinova el al. 2019). Improvements in the strength of wet web of base paper after the addition of MNFC have been also reported ( $\mathrm{Lu}$ et al. 2019, 2020), despite the decrease in the web solid content observed after pressing of the paper sheet containing MNFC (Lu et al. 2019). There are two main features that might explain the MNFC strengthening capacity. First, the surface area expanded by the nanoscale dimensions allows MNFC to act as an effective adhesion promoter. By filling the interstices within the fiber network, fibers can come closer together, increasing the fiber-fiber bonding and thus the total bonded area. Secondly, the tendency of MNFC to form entangled networks enhances the mechanical properties of the paper. The outstanding intrinsic strength of these nano-networks embedded along larger fibers provides the macroscopic network with points of high resistance, which improves the overall tensile strength (González et al. 2012). Additionally, the similarity found in the chemical structure of both MNFC and cellulosic fibers reduces chances of incompatibility when combining the biomaterials (Balea et al. 2016).

Several studies highlight how MNFC decreases porosity and air permeability when added into the sheet (Eriksen et al. 2008; Taipale et al. 2010; González et al. 2012; Sehaqui et al. 2013; Brodin et al. 2014; He et al. 2017; Balea et al. 2019; Kasmani et al. 2019). This decrease in porosity is caused by the MNFC bonding with the fibers in the sheet network, which closes off the porous structure (Brodin et al. 2014; He et al. 2017). Pore blockage increases when the content and fibrillation degree of MNFC used increases (Balea et al. 2019). Taipale et al. (2010) proposed that air permeability indicates the complexity of the resulting network.

The reduction in porosity with the addition of MNFC also correlates with an increase in paper density (Sehaqui et al. 2011; He et al. 2011). Brodin et al. (2014) suggests that MNFC behaves similarly to fines in regard to their ability to close pores in the sheet structure which increases the number of hydrogen bonds. Other studies also report a significant increases in sheet density (Eriksen et al. 2008; Manninen et al. 2011; Charani et al. 2013; Su et al. 2013). 


\section{Factors Affecting the Usage of MNFC as a Paper Strength Additive}

The goal of this section is to review the most important factors affecting paper strength when MNFC is added to papermaking furnishes. This must be considered with caution, not only because of very different pulp slurry conditions utilized in different published studies, but also because the efficiency of retention of the MNFC is rarely known or reported in such studies. Furthermore, in cases where the investigators have employed chemical-based strategies (retention aids or fixatives) to achieve relatively high retention efficiency in the course of their work, there can be profound changes in the uniformity of formation, and such differences can greatly affect the paper's strength and other characteristics.

In light of such uncertainties, results of studies in the absence of chemical additives will be regarded as a good source of information about the direction, but not the extent of resulting changes in paper properties, because in many cases it is not possible to estimate the MNFC content of the paper. By contrast, studies conducted with the participation of cationic polymers will be used as evidence of what magnitude of quantitative changes are possible, with the caveat that large differences in formation uniformity might reduce one's confidence in generalizing the published findings.

Though other reviews have discussed general aspects related to applications of MNFC in papermaking, there are still limitations regarding an integrated comprehension of the colloidal behavior of systems containing MNFC. To address such gap, this review will systematically discuss and analyze the latest studies on applications of MNFC in papermaking. For a better understanding, three sets of main parameters describing the colloidal behavior of systems comprised of MNFC, pulp fibers, and retention aids (or any other additive) are defined. These parameters are (1) intrinsic and extrinsic variables, (2) furnish composition, and (3) degree of dispersion. Any element included in these categories can be expected to affect the paper performance. This approach will give papermakers a clear overview of how to manipulate the MNFC application to tailor the final properties of the paper product.

The intrinsic variables describe the physicochemical nature of each of the components comprising the colloidal system, whereas extrinsic variables refer to the effect of outside parameters, such as temperature. This set can be further divided as follows:

- Properties of MNFC, affected by (i) morphology (a function of the production pathway, the fiber source used for manufacturing, and the intensity of the mechanical treatment applied), and (ii) chemistry (a function of the fiber source used for manufacturing, and the biological/chemical pre- and post-treatment applied, which will dictate the chemical composition).

- Properties of pulp fibers used as the paper matrix, affected by (i) pulp source, (ii) pulping method, (iii) lignin content, and (iv) degree of beating.

- Properties of additives, affected by (i) nature of the additive and (ii) addition strategy, i.e., the sequence of addition used to mix the MNFC, pulp fibers, and additive in the paper furnish.

- Bulk conditions, affected by (i) $\mathrm{pH}$ and (ii) salinity.

The furnish composition defines the relative amount of each of the species in the colloidal system, whereas the degree of dispersion relates to the mechanical protocol applied to disperse the species in the bulk of the paper furnish. Table 3 shows a breakdown of the sets of parameters previously defined. 
Table 3. Sets of Main Parameters Describing the Colloidal Behavior of Systems Comprising MNFC - Pulp Fiber - Retention Aid (Or Any Other Additive)

\begin{tabular}{|c|c|c|}
\hline \multicolumn{3}{|c|}{ Intrinsic and Extrinsic Variables } \\
\hline Property of: & Variable: & Determined by: \\
\hline \multirow{6}{*}{ MNFC } & \multirow{3}{*}{ Morphology } & $\begin{array}{c}\text { Fiber source* }^{*} \\
\text { (hardwood vs. softwood nanofibers) }\end{array}$ \\
\hline & & $\begin{array}{l}\text { Particle size* } \\
\text { (micrometric vs. nanometric) }\end{array}$ \\
\hline & & Degree of fibrillation* \\
\hline & \multirow{3}{*}{ Chemistry } & $\begin{array}{c}\text { Fiber source } \\
\text { (hardwood vs. softwood nanofibers) }\end{array}$ \\
\hline & & $\begin{array}{c}\text { Lignin content } \\
\text { (lignocellulosic nanofibers vs. cellulosic } \\
\text { nanofibers) }\end{array}$ \\
\hline & & $\begin{array}{c}\text { Surface modification } \\
\text { (carboxylation (TEMPO-oxidation), } \\
\text { carboxymethylation, periodate-oxidation, } \\
\text { quaternization, enzymatic hydrolysis) }\end{array}$ \\
\hline \multirow{4}{*}{$\begin{array}{l}\text { Papermaking } \\
\text { fibers }\end{array}$} & Source & $\begin{array}{l}\text { Virgin (hardwood, softwood) or recycled fibers } \\
\text { (deinked pulp) }\end{array}$ \\
\hline & Pulping method & $\begin{array}{l}\text { Thermomechanical pulping (TMP), chemi- } \\
\text { thermomechanical pulping (CTMP), Kraft, } \\
\text { Sulfite }\end{array}$ \\
\hline & Lignin content & Bleached or unbleached fibers \\
\hline & Degree of beating & Fiber fibrillation and fines content ${ }^{\star}$ \\
\hline \multirow{3}{*}{ Additives } & \multirow[t]{2}{*}{ Type of additive } & $\begin{array}{c}\text { Polyelectrolytes* } \\
\text { (Carbohydrates, amides, amines, quaternary } \\
\text { ammonium with cationic or anionic nature) }\end{array}$ \\
\hline & & $\begin{array}{c}\text { Fillers } \\
\end{array}$ \\
\hline & Sequence of addition & $\begin{array}{c}\text { Pre-mixture of polyelectrolyte and MNFC or } \\
\text { direct addition of components into paper } \\
\text { furnish* }\end{array}$ \\
\hline \multirow{2}{*}{ Bulk } & $\mathrm{pH}$ & \multirow{2}{*}{$\begin{array}{c}\text { Changes in } \mathrm{pH} \text { and salinity of paper furnish } \\
\text { containing MNFC }\end{array}$} \\
\hline & Salinity & \\
\hline
\end{tabular}

\begin{tabular}{|l|c|}
\hline \multirow{2}{*}{ Furnish Composition } & MNFC to additive ratio* \\
\cline { 2 - 2 } & MNFC to pulp fiber ratio \\
\hline Degree of Dispersion & Degree of MNFC dispersion in paper furnish \\
\hline
\end{tabular}

*: subjects discussed in this review

\section{Intrinsic and Extrinsic Variables}

Fiber source

The type of fiber used for the production of the MNFC has an important influence on the fibrillation development, fines generation, and subsequent performance of the nanocellulosic material (Stelte and Sanadi 2009; Lahtinen et al. 2014; Johnson et al. 2016). At similar levels of mechanical treatment, hardwood cellulose nanofibrils will produce a comparable but slightly weaker film, i.e., lower tensile strength, than softwood cellulose nanofibrils (Spence et al. 2010a,b). Thus, if the tensile strength of the resulting film is used as an indication of the fibrillation degree induced by the treatment, hardwood cellulosic 
fibers are harder to fibrillate than softwood fibers; i.e., they will require a higher level of pre-treatment and mechanical treatment (Stelte and Sanadi 2009; Vartiainen et al. 2015; Zhao et al. 2017).

Figure 4 shows scanning electron microscopy (SEM) images comparing the progression of hardwood fibrillation to the fibrillation of softwood fibers after a given number of passes through a refiner. Similarly, when using CNF as an additive to hardwoodbased pulp handsheets, hardwood CNF produces lower tensile and internal bond values compared to softwood CNF at a given fines content ( $<86 \%$ fines). However, for fines content above $90 \%$, the change in the handsheets properties is independent of the source used for the CNF production (Johnson et al. 2016).

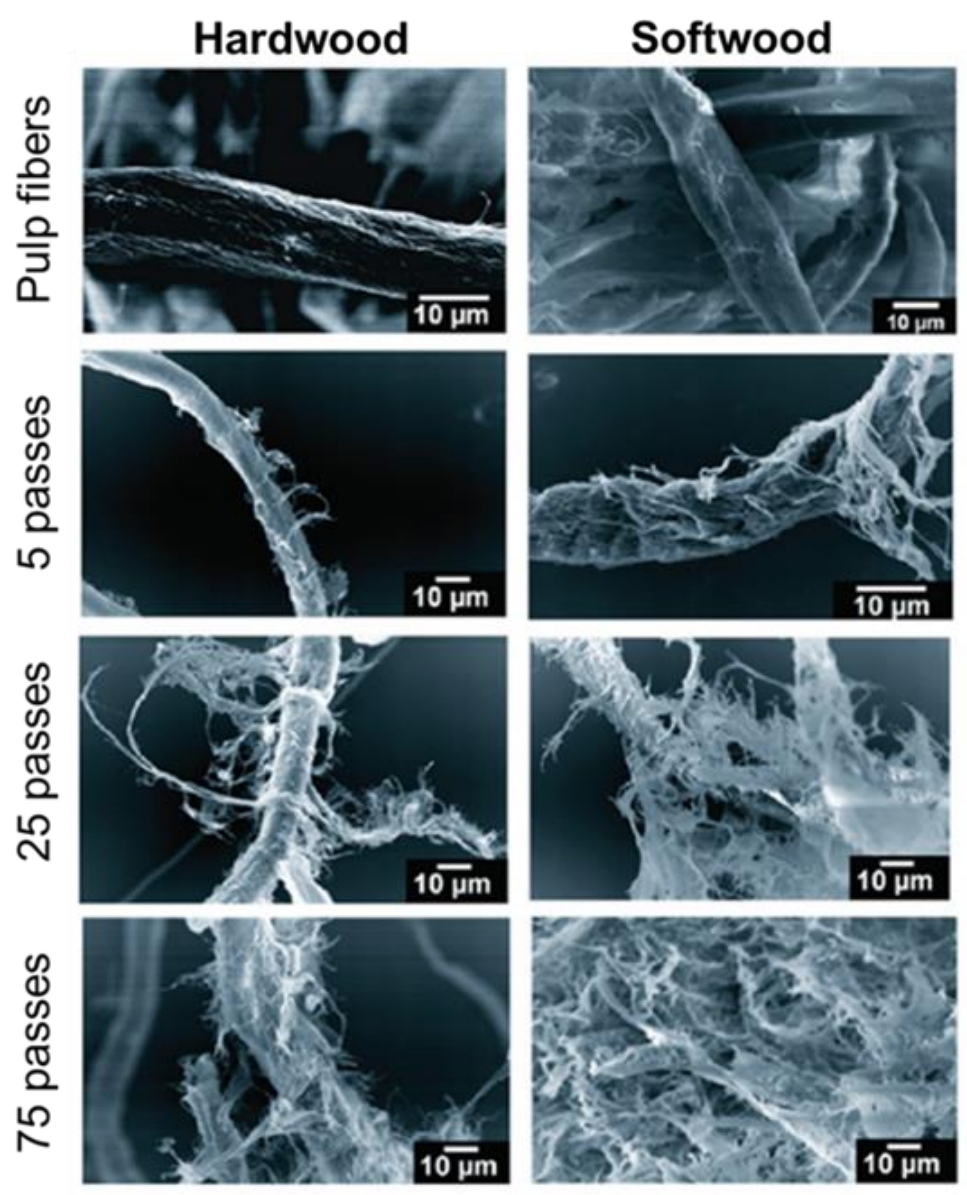

Fig. 4. SEM images comparing the fibrillation evolution for hardwood and softwood fibers after a given number of passes through a refiner (adapted with permission from Stelte and Sanadi 2009; Copyright 2009 American Chemical Society)

Results from this work suggest that at the nanoscale, the expanded surface area overcomes the chemical component inherent to the fiber source and that such surface area can also drive interaction between the $\mathrm{CNF}$ and the fiber network. Further research to assess the influence of different raw materials on the performance of nanocellulose when used as a paper strength additive needs to be conducted.

The chemical composition of the pulp fibers also plays a key role in the fibrillation process. A higher hemicellulose content facilitates the fibrillation of nanofibers during the mechanical treatment of the pulp (Iwamoto et al. 2008; Spence et al. 2010a,b). Also, it is 
proposed that lignin-containing fibers promote fibrillation because of lignin's antioxidant properties and its ability to stabilize radicals generated from cellulose during the grinding treatment (Ferrer et al. 2012; Solala et al. 2012). Results reported by Spence et al. (2010a,b) support Ferrer's 2012 finding that lignin-containing NFC produces films with comparable properties to their bleached counterparts. Higher lignin content was found to aid in the fibrillation process because the resulting nanofibrils have a higher surface area and lowest size fraction (Imani et al. 2019b). Alternatively, it is suggested that the presence of lignin and hemicellulose hinders the fibrillation process, especially when combined with TEMPO pre-treatment (Herrera et al. 2018; Syverud et al. 2011). A high content of hemicellulose may be detrimental for the fibrillation, as xylan does not have the C6 that is the oxidation position targeted by the TEMPO catalyst (Syverud et al. 2011). It should be noted that the studies cited here used different pulping processes, e.g., kraft, soda, semi-chemical, to produce the unbleached fibers for MNFC production. Therefore, the discrepancies in performance could be due to the different pulping environments influencing the remaining lignin structure in the fibers. For example, during the kraft process sulfate groups will be added to the lignin structure as it is being degraded, but the sulfate groups are not present in the soda process. So far, studies have only concerned themselves with the amount of lignin remaining with the cellulose before fibrillation, which makes it hard to draw a conclusion on how the different degradations of the lignin structure influences fibrillation.

When evaluating papermaking applications, the blending of lignin-containing nanocellulose into fiber sheets improves the overall strength profile; however, it has been shown to be less efficient than using lignin-free nanocellulose (Osong et al. 2014). Before reaching a definitive conclusion, more research should focus on how the presence of lignin alters the performance and reinforcement capabilities of the MNFC in targeted papermaking applications. For example, there is evidence suggesting that even though lignin-containing MNFC could be suitable as a bulk additive in papermaking, it would make a poor coating additive compared to lignin-free MNFC (Imani et al. 2019a).

\section{Particle size (micro vs. nano) and degree of fibrillation}

The size of fibrils and the degree of fibrillation, the latter referring to the homogeneity of the fibrillated sample, largely determine the colloidal features of pulp suspensions containing MNFC. The colloidal interactions exhibited by particles at the micro- and nanoscale result from a balance between electrostatic and dispersion forces governing the system. Any change in the degree of fibrillation contributing to increase the surface area will also result in a higher surface charge, directly affecting the colloidal behavior among cellulosic fibrils (Hubbe 2007b; Hakeem et al. 2015; Saarikoski et al. 2017).

The fibril size plays a key role in the resulting properties of paper when MNFC is incorporated in pulp suspensions. The MNFC with a small particle size produces a paper with greater bonding strength and denser structure, but it also results in lower retention. In contrast, MFC with a broader particle size distribution shows less improvement in mechanical properties but more efficient retention in the fiber web (Su et al. 2014). Madani et al. (2011) reduced the average fibril length of MFC from $221 \mu \mathrm{m}$ to $100 \mu \mathrm{m}$ by applying a gel fractionation technique. Composite papers formed by $10 \%$ addition of MFC to chemical wood pulp showed $25 \%$ increase in tensile index for non-fractionated MFC and an additional 10\% improvement for fractionated MFC. Eriksen et al. (2008) also reported an increasing tensile index in TMP paper by decreasing the average particle size of MFC. However, the authors also claimed that mechanical processing beyond a specific energy

Zambrano et al. (2020). "Nanocellulose \& grammage," BioResources 15(2), 4553-4590. 4566 
consumption does not translate into a significant further increase in tensile strength. They observed a drop in tensile index from a maximum value when the degradation of homogenized MFC was successively increased beyond that point. From this study, it is possible to infer that there is an optimal fibrillation degree that will yield a maximum improvement in tensile strength. Any additional energy input beyond this limit will represent an energy loss in the overall energy balance associated with MFC manufacturing. In agreement with this logic, He et al. (2017) concluded that MNFC production should be focused on tailoring the properties of the fibrillated fibers to be incorporated into a specific application, i.e., achieving an optimal degree of fibrillation for a given application, rather than trying to retrofit MNFC, whose dimensions are completely nanoscale, to possible applications.

Fibrillation also has an important influence on the mechanical properties of nanocellulose films. The NFC with a high degree of fibrillation can be more easily dispersed in the bulk suspension prior to sheet formation. As a result, a more homogeneous distribution of the defects and vulnerable locations for initiation of failure within the network is obtained, which consequently improves the strength and rigidity of the nanostructure (González et al. 2014). A reduction in the average fibril size also results in more fiber bridging through both mechanical interaction and $\mathrm{H}$-bonding. However, excessive mechanical treatment has the potential to reduce strength properties due to a possible reduction in the length of the fibrils (Stelte and Sanadi 2009).

The degree of fibrillation influences the dewatering capacity of pulp suspensions and the solid content of the paper after wet pressing. He et al. (2017) described an increase in the drainage time as a function of the degree of fibrillation of CNFs, which was accompanied by an overall reduction in the degree of polymerization, zeta potential, and degree of crystallinity. As the fibrillation of fibers progresses, particles are more easily incorporated into the fiber web. However, this partially closes the pores between fibers, limiting the ability for the wet web to drain water. The CNFs also hinder drainage due to its increased water retention capacity, which may be the cause of the reduction in solids content observed after wet pressing.

Besides favoring the reduction of the high-energy demand associated with mechanical fibrillation processes, the pre-treatment of cellulose fibers also aims to improve the achievable degree of fibrillation (Isogai 2013). Delgado-Aguilar et al. (2015) evaluated the reinforcing ability of five types of CNFs prepared by different pre-treatments (chemical, mechanical, and enzymatic) when combined with papermaking pulps. The CNFs with a high degree of fibrillation and a large specific area, e.g., TEMPO-oxidized $\mathrm{CNF}$, showed the best performance as paper strength additives. However, it was shown that CNFs with a smaller degree of fibrillation could also induce an equivalent increase in the mechanical properties by using a higher load compared to that of TEMPO-oxidized CNFs. A similar observation was made by Johnson et al. (2016), who claimed that similar values of paper strength could be reached by either adjusting the CNF loading level or the CNF fines content. As shown in Fig. 5, the authors found that changing the fines content in the CNF from $77 \%$ to $94 \%$ did not affect the performance in terms of tensile index. This held at all the levels tested for CNF load in the handsheets. The findings also support the idea that there are diminishing returns in strength improvements past a certain MNFC degree of fibrillation. 


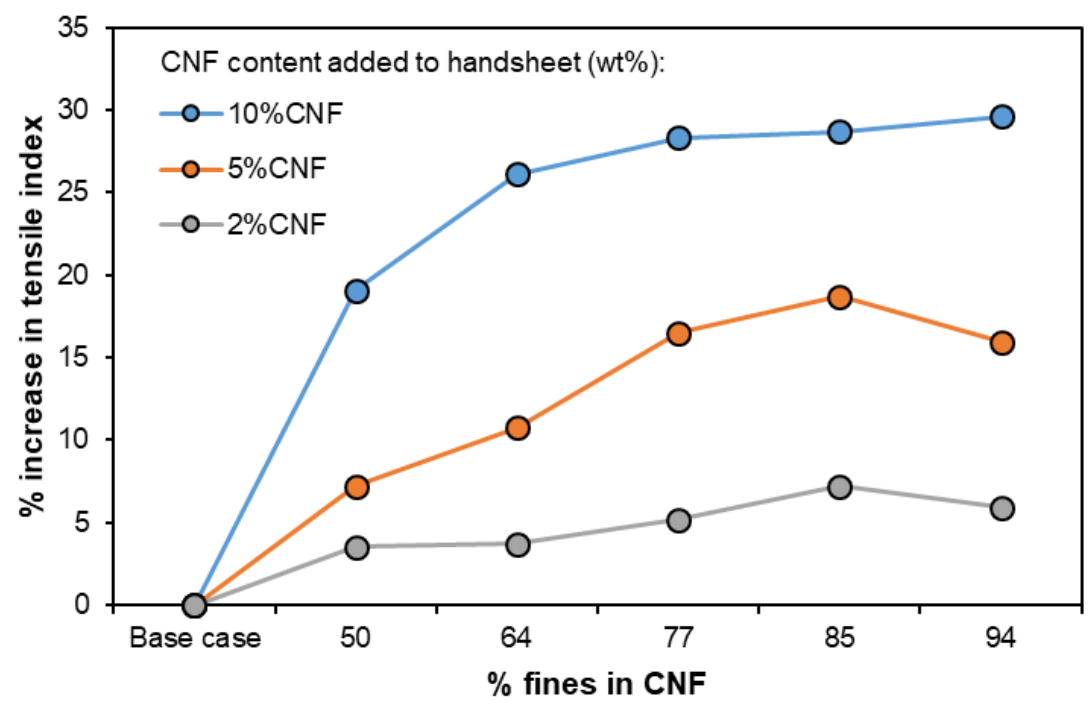

Fig. 5. Effect of addition of CNF with different fines content on the tensile index of handsheets (no retention aids were used) (adapted from Johnson et al. 2016)

\section{Degree of Beating of Papermaking Fibers}

Fibrillation and fines content

Mechanical refining of papermaking fibers increases the number of fiber-to-fiber bonds, thus producing a stronger paper. The mechanisms of shearing and compression forces involved in this process completely transform the original characteristics of the fibers. The increase of external fibrillation enlarges the fiber surface area and creates fibrils from the primary and secondary wall. Fines are also produced when the primary and secondary wall fibrils are cut off from the fibers (Smook 2016). These factors might affect the reinforcing features of the MNFC due to a change in the interaction with the pulp fibers in suspension and during the sheet formation.

Several authors have suggested that an increase in the external fibrillation of pulp fibers inhibits the enhancement that MNFC has on fiber-fiber bonding. Su et al. (2013) compared the strength development resulting from the blending of MFC with unrefined fibers and fibers refined at 10,000 rpm in a PFI mill. The addition of MFC into unrefined fibers resulted in a radical increase in the dry strength in contrast to the dry strength of composites made from the mixture of refined fibers and MFC, which exhibited a small variation despite the MFC content added. Afra et al. (2013) evaluated the effect of NFC addition on the properties of paper made from softwood pulps beaten to 350 and $550 \mathrm{CSF}$. As a recurrent trend, the increase in the tensile strength of the paper prepared with $550 \mathrm{CSF}$ softwood fibers was greater than the increase obtained with the 350 CSF fibers ( 72\% vs. $\sim 60 \%$ ).

González et al. (2012) studied the physical, morphological, and mechanical properties of paper sheets reinforced with TEMPO-oxidized NFC using unbeaten and slightly beaten Eucalyptus slurries. An analysis of that study conducted by Boufi et al. (2016) showed that an addition of $3 \mathrm{wt} \%$ NFC produced an increase of approximately $24 \%$ in the tensile index, which was similar for both beaten and unbeaten pulps. Conversely, after addition of $6 \mathrm{wt} \% \mathrm{NFC}$, the increase in tensile index shown by the unbeaten pulp was $67 \%$ while only a $45 \%$ increase was obtained for the slightly beaten pulp. A similar trend was found by Taipale et al. (2010). The authors obtained increments of $73 \%$ and $35 \%$ in

Zambrano et al. (2020). "Nanocellulose \& grammage," BioResources 15(2), 4553-4590. 4568 
tensile index of the paper after adding NFC to a softwood pulp beaten for 10 and $30 \mathrm{~min}$. In this case, a cationic starch dosage of $15 \mathrm{mg} / \mathrm{g}$ dry pulp was used.

The presence of fines in pulp fibers might also affect the MNFC performance when added into pulp furnishes. Potulski et al. (2014) reported an increase of $258 \%$ in tensile index after the incorporation of microfibrillated cellulose to bleached Eucalyptus pulp with a low refining level $\left(15^{\circ} \mathrm{SR}\right)$, compared to an increase of $41 \%$ obtained after adding an equivalent amount of MFC to the same pulp but at a higher degree of refining $\left(25^{\circ} \mathrm{SR}\right)$. The authors ascribed the difference observed to the fact that the combination of refining and addition of MFC generates a larger number of fines in the system that imposes limits on increasing the tensile strength of paper. Furthermore, after examining the work by González et al. (2013) covering the effect of the combination of enzymatic treatment (biorefining) and NFC addition on the mechanical properties of paper, Boufi et al. (2016) stated that González's study supports the theory that the fibrillation of refined pulps is the variable limiting the performance of NFC in papermaking. This is because the bio-refining process does not generate the amount of fines that is typically generated during the traditional pulp refining. It has been also reported that the presence of fines negatively impacts the drainage properties of pulp suspensions containing MFC, even with the presence of cationic polyelectrolytes. Taipale et al. (2010) showed that after removing the fines from a beaten pulp suspension (the pulp was beaten for $60 \mathrm{~min}$ ), the drainage of the furnish depended less on both the MFC content and type of polyelectrolyte used.

The results just discussed reinforce the hypothesis postulated by Brodin et al. (2014) that CNF shows its best performance in fiber networks where poor fiber bonding is the variable hindering the tensile strength. For that reason, the addition of MNFC in paper furnishes comprised of beaten chemical pulps is less likely to significantly enhance the mechanical properties of paper sheets in comparison to the addition in unbeaten pulp furnishes. It is also worth noting that although the percentage of change in tensile index decreases with the fiber fibrillation, the tensile index value obtained by combining defibrillation of pulp fibers and MNFC addition is greater compared to that obtained when MNFC is simply added to a pulp slurry of unbeaten fibers.

Despite seeing a better MNFC performance when adding it to unbeaten furnishes, several authors have stated that the gains in tensile index obtained by the addition of MNFC to a pulp furnish are similar to what could be obtained by beating the original pulp suspension before the sheet formation. Sehaqui et al. (2013) studied the mechanical properties of handsheets made of $10 \%$ NFC and $90 \%$ softwood pulp fibers subjected to varying levels of beating. The authors reported that the addition of NFC to non-beaten pulp fibers had a similar effect on tensile index as beating a $100 \%$ softwood fiber furnish because both strategies resulted in a high-density sheet. Hollertz et al. (2017) described the same trend for unbleached kraft pulp sheets containing either carboxymethylated CNF or kraft MFC with different loadings. However, that relationship between tensile strength and density was not found when chemically modified CNFs (periodate-oxidized CNFs and dopamine-grafted CNFs) were introduced into the paper furnish using polyvinyl amine (PVAm) as a retention aid, as shown in Fig. 6a. In this case, the tensile strength was significantly above the beating curve. Taipale et al. (2010) also stated that the results obtained through the addition of MFC without cationic starch considerably mimicked the results obtained with simply beating the bleached softwood kraft pulp and using no MNFC. As shown in Fig. 6b, slightly higher tensile strength values were attributed to the MNFC with more fibrils compared to the fibrils present on fibers generated during the beating process. Nevertheless, the combination of carboxymethylated MFC and cationic starch 
significantly increased the tensile strength compared to the tensile strength seen with just the beaten fibers at the same drainage rate. The underlying mechanisms yielding these results are discussed in the following section of this review.
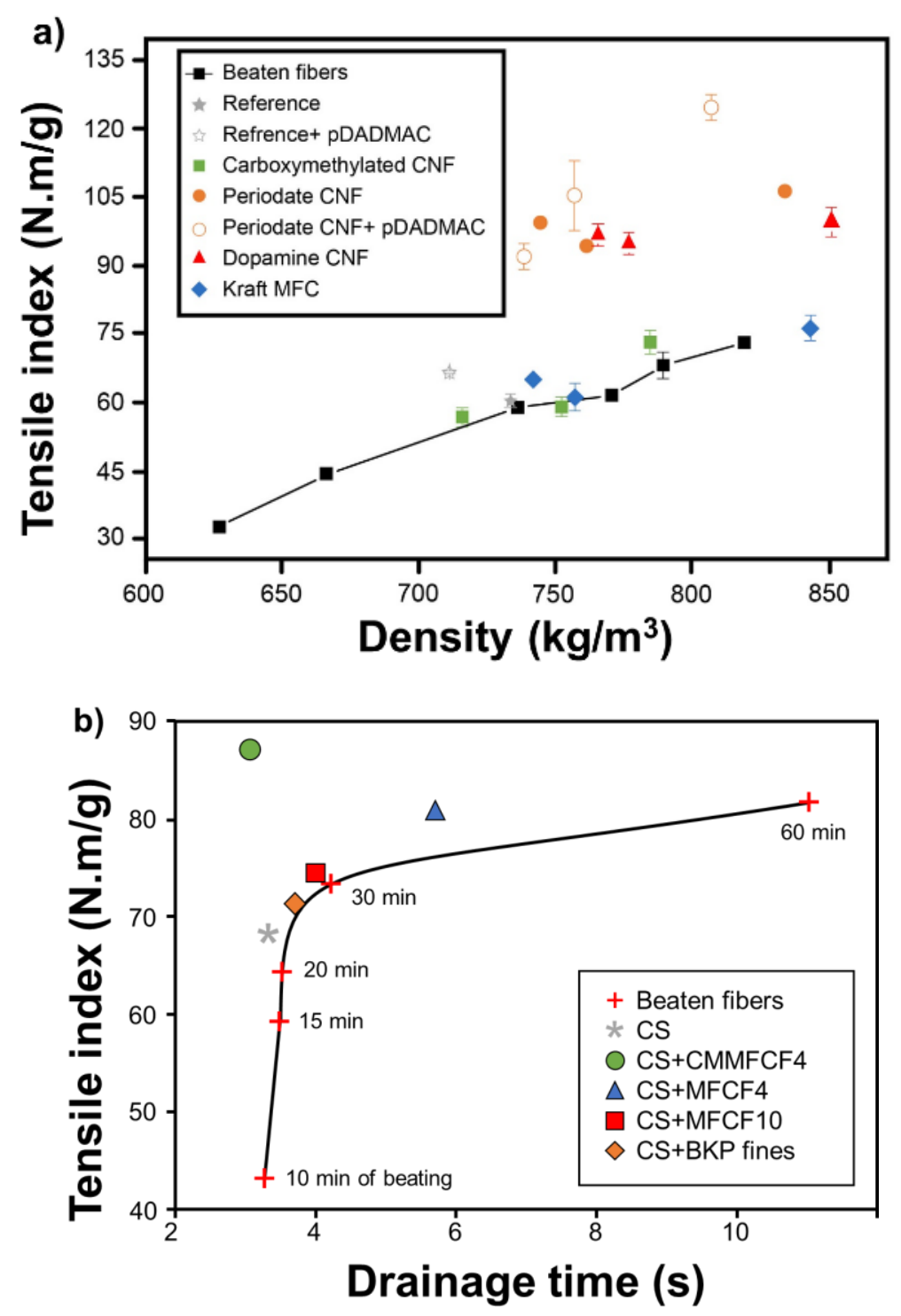

Fig. 6. Comparison between addition of MNFC and mechanical beating of pulp fibers as strategies to increase the tensile index of paper sheets: (a) different types of chemically modified CNFs added to a 4000 PFI-revs beaten pulp using $2.5 \mathrm{mg} / \mathrm{g}$ PVAm as retention aid or, if indicated, polyDADMAC; (b) different types of MFCs added to a 10 min beaten pulp using 15 $\mathrm{mg} / \mathrm{g}$ of cationic starch (CS) as fixative. F4 and F10 indicates that the pulp was passed through a fluidizer unit either four or ten times respectively. CMMFC is a carboxymethylated MFC sample (adapted from Taipale et al. 2010; Hollertz et al. 2017)

\section{Type and Addition Point of Additive}

\section{Polyelectrolytes}

Polyelectrolytes showing diverse chemical nature and surface charge density are commonly introduced in the pulp slurry to improve the retention of fines particles during sheet formation. Using polyelectrolytes, best-known as retention aids (RA) and dry 
strength agents (DSA), is considered a proven strategy in conventional paper machine operations. Retention aids represent one of the most suitable ways that researchers are currently focusing on to increase the retention of MNFC in the sheet. In this sense, factors related to the chemical structure of the polyelectrolyte, bulk concentration of both MNFC and retention aids, as well as the sequence of addition, are main variables affecting the system performance.

The typical chemical species studied for their use as retention aids and possibly as dry strength agents are long molecular chain polymers with a cationic nature. Four main families of polyelectrolytes used in combination with MNFC have been identified: (i) carbohydrates, e.g., cationic starch (CS), xyloglucan, and chitosan (CH); (ii) polyvinylamines (PVA); (iii) polyacrylamides, e.g., c-PAM, c-PAM-B; and (iv) cationic polymers with quaternary ammonium, e.g., polyamidoamine-epichlorohydrin (PAE) (Boufi et al. 2016).

The chemical structure of the cationic polymer will influence the way MNFC interacts with it, i.e., the balance between non-electrostatic forces, electrostatic forces, and flocculation mechanism. The use of MNFC in pulp slurries containing polyelectrolytes has been shown to increase the flocculation and stability of the particle flocs. MNFC increases the floc stability in the presence of CS due to the formation of hydrogen bonds, regulates the negative effect of increasing PAM dose on floc stability, and increases the floc size when combined with PVA. Therefore, the particular interaction between MNFC and the cationic polymer will be the crucial factor affecting the retention of the nanoparticles within the fiber network (Merayo et al. 2017a). Besides improving retention, some polyelectrolytes can also boost the strengthening effect of MNFC by generating synergic effects within the paper web. The most important strength improvements reported in the literature correspond to cases where MNFC has been combined with a polyelectrolyte (Ahola et al. 2008; Taipale et al. 2010; Boufi et al. 2016; Hollertz et al. 2017; Rice et al. 2018; Yousefhashemi et al. 2019). Moreover, the use of retention aids has been shown to improve the dewatering of pulp suspensions containing MNFC (Merayo et al. 2017b). These synergistic behaviors will only occur if the correct retention aid chemistry for a system is implemented.

Merayo et al. (2017b) studied possible synergies between MFC and RAs to improve recycled paper strength while avoiding negative effects on the drainage process. Five different RAs were considered: PVA, CH, CS, c-PAM, and c-PAM-B (which is formed by a formulation of polyamine as coagulant, PAM, and hydrated bentonite clay). As a common feature, all the RAs improved water drainage and retained approximately $90 \%$ of the solid particles. A comparison made at the lowest dose tested, which was representative of the dosages used in industrial applications, showed that c-PAM and c-PAM-B were the most efficient in reducing drainage times, followed by $\mathrm{CH}$. The PVA also provided good results with a dosage ten times higher than commercially viable doses. The CS was the least effective in reducing drainage times, especially at low and moderated doses.

Regarding mechanical properties, the addition of MFC using c-PAM-B resulted in the best formation uniformity of the paper and the higher tensile index increase (15\%). According to the authors, bentonite, an anionic component found in this RA, kept a good dispersion of MFC in the pulp despite the presence of PAM, which is known for promoting a high floc formation. No synergy was observed between MFC and c-PAM. The highest values of tensile index were obtained with pulp containing $1 \% \mathrm{MFC}$ when $\mathrm{CH}$ was used as $\mathrm{RA}$. The $\mathrm{CH}$ itself did not affect tensile index; however, in combination with MFC, a synergistic effect developed, enhancing the paper strength. The use of MFC and PVA 
provided a tensile increase of $15 \%$ at its highest point, and for the case of CS, addition of MFC showed a negative synergy that decreased the tensile index. The authors claimed that $\mathrm{CS}$ might be interacting with MFC in the pulp, resulting in flocs that favor retention but worsen formation uniformity. At the same time, this might decrease the interaction between MFC and fibers. From this study, it is important to note that some RAs required the addition of MFC to the pulp to recover the tensile index that the paper originally shows without the presence of any additive. For example, c-PAMs provided the lowest drainage time at expenses of a high floc formation, which favors faster drainage but hinders fiber bonding. Thus, a balance between flocculation and bondability will also be required in this case, and attention needs to be taken when dealing with additives exhibiting such features.

Similarly, Taipale et al. (2010) studied the effect of the addition of MFC and fines on the drainage of a kraft pulp suspension and its relation with paper strength. Five polyelectrolytes were evaluated for this purpose: three different types of c-PAM, polyDADMAC, and CS. First, contrary to the results obtained by Merayo et al. (2017b), an increase in the drainage time was obtained in the presence of c-PAM and MFC. According to the authors, high molar mass c-PAMs tend to form a thick, loose, and viscoelastic layer with the added MFC that might increase the water retention capacity of the network. Secondly, compacted networks formed by the addition of polyDADMAC allowed faster drainage as the low molar mass high charge density polyelectrolyte adsorbs in a flat conformation leading to thinner layers of polymer and MFC. Finally, highly branched CS with a very high molecular mass only slightly decreased the drainage. The authors reported a strong dependence between the type of polyelectrolyte and the drainage for suspensions containing fines. As a common trend, it was stated that addition of MFC causes an increase in the strength of the paper, which can be enhanced when CS is used as a fixative. Although a reduction in the drainage rate consistently accompanied this effect, the authors also found that by adding carboxymethylated MFC in combination with CS it was possible to double the tensile strength without decreasing the drainage rate. They attributed this finding to the small size and high-density charge of the anionic MFC that would allow the formation of a thin MFC layer on the CS previously adsorbed onto the fiber surface. As a result, MFC nano-networks would be coating the fibers rather than filling the voids between them, leaving more open pores for water to freely drain from the sheet.

Likewise, Hollertz et al. (2017) showed how cellulose micro- and nanofibrils exposed to different chemical modifications can be effectively used as strengthening additives in papermaking. The authors considered carboxymethylated CNFs as the starting reactant to produce two types of modified CNFs: periodate-oxidized carboxymethylated and dopamine-grafted carboxymethylated. These three different CNF were added to a pulp suspension of unbleached kraft pulp with and without PVAm used as a retention aid. In this case, an increase in the tensile strength index of $56 \%$ was obtained with as little as 2 wt $\%$ periodate-oxidized CNF added. The authors found that PVAm promotes the adsorption of periodate-oxidized CNF on the fiber surface before dewatering rather than its attachment in the pores between the fibers during dewatering. As a result, a higher dewatering rate was obtained for periodate-oxidized CNF compared to that of the sheets prepared with dopamine-grafted CNF and a conventional kraft MFC. This coating-like conformation is similar to the one reported by Taipale et al. (2010) for sheets made with the addition of carboxymethylated CNF in combination with CS. Therefore, based on the results obtained from the previous studies, it is possible to state that retention aids affect the conformation of the fibrillated material onto the cellulosic fibers, and the resulting 
arrangement is what will dictate the extent of improvement in strength and drainage rate obtained in the paper product.

The formulation and addition of cationic polyelectrolyte complexes (CatPECs) onto papermaking furnishes containing MNFC, as well as the pretreatment of the nanofibers with cationic polymers, has also been explored. Schnell et al. (2019) evaluated the efficiency of PECs to improve the reinforcing capacity of lignocellulosic micro/nanofibers (LCMNF) while reducing the drainability problems caused by the fibrillar material. CatPECs were prepared by mixing polyacrylic acid with poly(allylamine hydrochloride). The combination of CatPECs with LCMNF increased the tensile strength of the paper sheet compared to a reference sheet with no additives. The highest improvement $(+48 \%)$ corresponded to the CatPEC dosage required to reach the charge neutrality of the system ( $0.75 \%$ based on pulp) in a papermaking furnish containing $3 \%$ LCMNF. At this dosage, the negative effects on drainage caused by the LCMNF were minimized, and the retention of fines and LCMNF were maximized as determined by the Britt Dynamic Drainage Jar test.

Rice et al. (2018) evaluated the performance of NFC pretreated with cationic starch as a bonding system in $350 \mathrm{~g} / \mathrm{m}^{2}$ handsheets made from bleached kraft pulp (70\% hardwood and $30 \%$ softwood). NFC pretreated with cationic starch was particularly effective in improving the tensile strength and stiffness of low-refined pulp mixtures (473 mL CSF) compared to high-refined pulp mixtures ( $283 \mathrm{~mL} \mathrm{CSF}$ ). Such a strategy allowed improved tensile strength at a lower apparent density (higher bulk) of the handsheets, which the authors suggest could be used as a means of substituting the mechanical refining of the pulp mixture in preparation of specific paper grades. It was proposed that cationic starch enhances the retention of NFC in the paper web and NFC simultaneously acts as an extender for cationic starch, which results in a synergistic action that improves paper strength. At the same time, a "spring-back" effect of the NFC-starch complex due to the elastic character of NFC might help to regain bulk of the paper web after wet-pressing (Hubbe 2019). Additional treatment of the cationic starch-treated NFC with colloidal silica was also employed to promote better dewatering of the pulp slurry.

\section{Sequence of addition}

The colloidal behavior of systems comprising MNFC, pulp fibers, and polyelectrolytes might be sensitive to the sequence used to introduce each substance into the pulp suspension. However, not many systematic studies assessing the influence of the addition strategy on the final properties of paper have been published. Ahola et al. (2008) studied the differences in addition strategies of CNF and PAE onto cellulose fibers. According to the sequence of addition considered, two configurations were obtained: a bilayer system for the case where CNF was added to pulp suspension containing the retention aid and nano-aggregates when the CNF was pre-flocculated with the retention aid and then added to the pulp suspension. The adsorption of PAE and nanofibrils as a layer-structure translated into a significant increase in both dry and wet tensile strength of paper. Conversely, cationic aggregates did not significantly improve the paper strength properties. He et al. (2017) investigated the effect of the addition method of cellulose nanofibrils into the wet-end of the papermaking process. Two different addition strategies were assessed: a precipitated calcium carbonate (PCC)-CNF composite filler and a wet-end additive. CS and c-PAM were used to promote binding and improve retention. Handsheets dosed with the composite filler showed a higher solid content than the CNF-added sheets after wet pressing; however, in both cases, a similar tensile strength was obtained. 


\section{Furnish Composition}

MNFC to polyelectrolyte ratio

Taipale et al. (2010) reported a linear increase of tensile index with increasing addition of MFC in a pulp suspension containing cationic starch. Conversely, Merayo et al. (2017b) found a decrease in the tensile index with increasing addition of MFC to pulp slurries containing $\mathrm{CH}, \mathrm{CS}$, and PVA as retention aids. Moreover, increasing the concentration of retention aid did not cause significant improvements in the tensile index, which even decreased in some cases. For these systems, the results suggest that retention of MFC is not the variable driving the decrease in tensile strength. According to the authors, high concentrations of MFC do not necessarily increase paper strength as the effect of poor paper formation can overcome the reinforcing capacity of MFC. Similarly, Hollertz et al. (2017) stated that retention aids do not significantly increase the fibril content in handsheets prepared using chemically modified CNF and PVAm as a retention aid. The authors rather attributed the self-retention capacity shown by these CNFs to their large size and a high degree of aggregation.

\section{Degree of Dispersion}

Degree of MNFC dispersion in the paper furnish

There is a proportional correlation between the dispersion degree of the species in a pulp suspension and the mechanical properties of the resulting paper sheets. Especially, for colloidal systems comprising MNFC, pulp fibers, and polymers, the energy input provided by hydrodynamic shear will affect the dispersion and thus the distribution of each component within the fiber matrix (Alcalá et al. 2013; Campano et al. 2018). Given the viscous features of the gel in which nanocellulose is normally produced, its homogenization in aqueous medium proves more difficult compared to cases where there is a dilute dispersion of nanofibers (Osong et al. 2016). Furthermore, as the tensile strength of a paper sheet depends mostly on the weakest bonds in the fiber network, a poor distribution of MNFC in the pulp furnish will translate into a non-optimum performance of the fibrillated component when used as a paper strength additive.

Based on this logic, Alcalá et al. (2013) studied the effect of the number of revolutions applied during dispersion on the performance of NFC within an unbleached Eucalyptus fiber matrix. The authors found a gradual decrease in porosity and a linear evolution of density with the addition of NFC. Nevertheless, after achieving the highest increase of density corresponding to samples with $9 \mathrm{wt} \%$ NFC, further addition caused a drop in these properties, as shown in Fig. 7a. The authors claimed that an increase in the NFC content in the paper slurry requires higher energy input to promote a homogeneous dispersion and result in a denser composite with a better interaction between the nanofibrils and the larger fibers. This hypothesis was corroborated after dispersing fiber slurries containing $3 \mathrm{wt} \% \mathrm{NFC}$ at different revolutions. Figure $7 \mathrm{~b}$ shows that there was an increase of $18 \%$ in tensile strength when the number of revolutions was increased from 180,000 to 240,000 . The authors stated that above $3 \mathrm{wt} \%$, properly dispersion of NFC is one of the key factors to boost the reinforcing capacity of the material for composites manufacturing.

In a similar effort, Campano et al. (2018) studied the mechanical and chemical dispersion of cellulose nanofibrils to improve its reinforcing effect on recycled paper. For the experimental conditions, the amount of CNF was fixed at $1.5 \mathrm{wt} \%$, and c-PAM and $\mathrm{CH}$ were selected as retention aids. The authors reported an increase of approximately $9 \%$ and approximately $15 \%$ in tensile index when the pulping time of the recycled pulp mixed with CNF was increased from $10 \mathrm{~min}(30,000$ revs) to $60 \mathrm{~min}$ (180,000 revs) using c-PAM and 
$\mathrm{CH}$, respectively. A significant decrease in porosity accompanied this increase. According to the authors, porosity is one of the signs that indicate a homogeneous dispersion and higher retention of the $\mathrm{CNF}$ within the fiber network. It was also determined that the temperature used during pulping (referring to pulping as pulp disintegration) does not have any effect on the dispersion of the CNF, as similar results in tensile index were obtained for $20^{\circ} \mathrm{C}$ and $50{ }^{\circ} \mathrm{C}$ for the same pulping time.

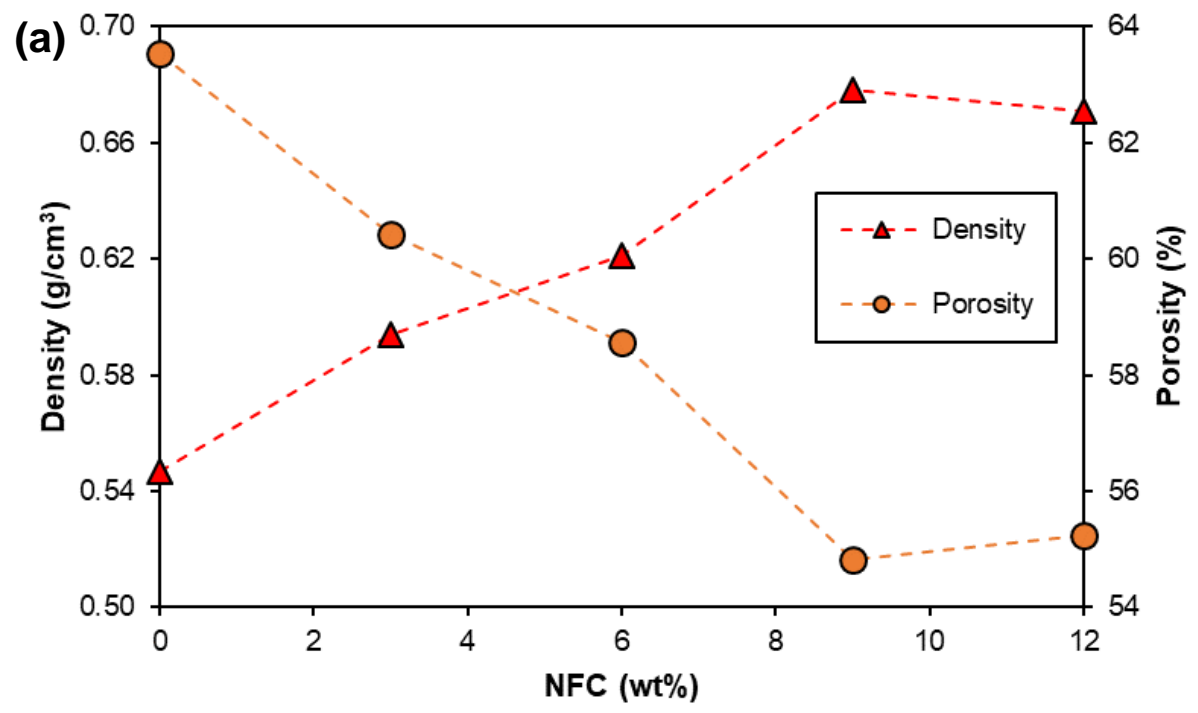

(b)

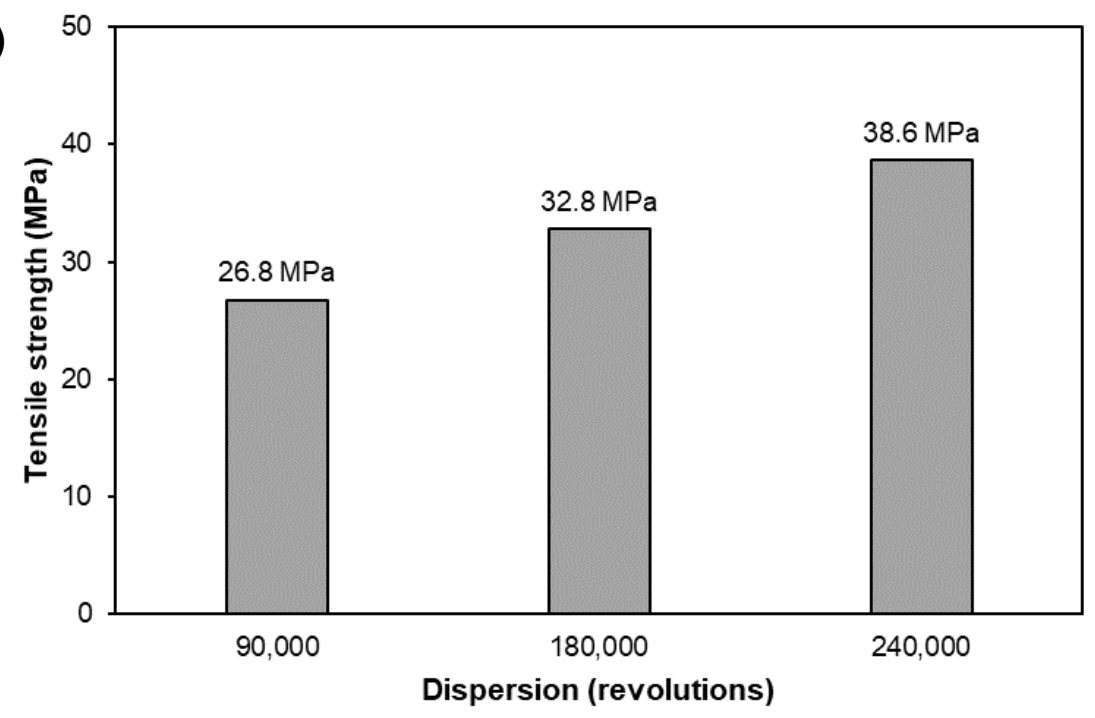

Fig. 7. Evolution of physical and mechanical properties of unbleached Eucalyptus pulp: (a) reinforced with different contents of NFC dispersed at 180,000 revolutions; (b) reinforced with 3 wt\% NFC using a different number of revolutions for dispersion (adapted from Alcalá et al. 2013)

Finally, the combination of dispersing agents in low concentrations $(0.003 \%)$ with the $\mathrm{CNF}$ allowed a reduction in the pulping time. This result was attributed to more effective dispersion of the CNF; however, the increase in the tensile index from shorter pulping times was not as large as the increase obtained with longer pulping times $(20.6 \%$ versus $30.0 \%$ ). Ultimately, the dispersion strategy to implement in each process will depend on practical considerations. The mechanical properties of paper sheets reinforced 
with MNFC depend not only on the combination of intrinsic and extrinsic variables and the furnish composition discussed in the previous sections. The influence of the degree of dispersion of the papermaking furnish also plays a fundamental role before the formation of the paper sheet. Therefore, as mixing of the MNFC with the larger fibers is a required step for fabrication of composites, taking advantage of this process could result in more efficient use of the nanocellulose. Currently, there are different approaches applied in the industry to increase the mechanical properties of paper. Many of them consist of modifying raw materials, which greatly increase the production cost. However, a clear understanding of the effects that mixing has on the distribution of the MNFC into a fiber furnish could allow papermakers to obtain outstanding results by changing the mixing process rather than modifying the raw materials. As an example, the basis weight, which is a critical variable contributing to the mechanical resistance of the paper sheet, could be easily reduced and the losses in paper strength could be compensated with the addition of MNFC under the proper mixing conditions.

\section{ECONOMIC POTENTIALS OF MNFC AS A DRIVER FOR FIBER REDUCTION}

\section{What Is the Paper Strength Expected by Consumers?}

There are at least three main influencers on paper strength: (i) individual fiber strength and their arrangement in the sheet, (ii) the intensity of the fiber-fiber bonds, and (iii) aspects of the feedstock raw material, such as fiber length distribution (Ankerfors et al. 2013). Additionally, as already discussed, the uniformity of formation within the paper sheet also can profoundly affect paper strength. Long fibers generally produce a sheet with a higher tensile strength compared to short fibers (Page 1969), which is because they have more sites to bond with multiple fibers. Paper is stronger in the machine direction than the cross-direction due to fibers preferentially arranging themselves lengthwise in the machine direction. Ultimately, tensile failure of paper occurs because of the interaction between interfiber bonding and fiber failure. Products, such as printing and packaging grades, have well developed fiber-to-fiber bonds, and it is expected that the sheet will fail due to broken fibers. Page's famous 1969 theory proposes that while the sheet is under a load, fiber bonds will start to fail. As the fiber bonds start to fail, there will be fewer bonds in the rupture region to disperse the load, causing individual fibers to take on more load until reaching their rupture strain. Tissue grades have relatively weak fiber-to-fiber bonds, which will cause the sheet to fail due to the breaking of fiber-to-fiber bonds instead of the breaking of individual fibers.

The strength requirements of paper products depend on the grade and final application. For printing and writing grades, tensile strength is needed to feed the sheet through the printers. Similarly, for tissue paper tensile strength is needed to withstand strain and stresses in the tissue machine and converting operation. The challenge with tissue is that most of the things that are done to help improve tensile strength hinder other desirable properties such as bulk and softness. Although a reduction in the tensile strength will improve the bulk and softness of the tissue sheet, if the tensile strength is too low, then the sheet will not support itself on the paper machine (De Assis et al. 2018b). In packaging grades, paperboard strength (usually ring crush or burst) is critical because all containerboards are rated for a certain cargo loading.

The easiest way to produce a stronger sheet of paper is to add more fiber to prepare a unit area of paper sheet (increase in basis weight). End-use customers are not concerned 
with how much fiber is used to produce their paper; they are mainly concerned with the final paper strength (along with softness and bulk for tissue grades). This can be seen with the use of filler in printing and writing grades. Fillers are significantly cheaper than fiber so companies use as much filler as they possibly can without negatively impacting the paper properties (He et al. 2017). This fulfills the customer's expectation while keeping the cost as low as possible, which translates into a higher profit margin. It has been shown that by introducing MNFC into a papermaking furnish, the strength properties of the paper can be increased. However, customers generally are not willing to pay a premium for an enhanced strength (De Assis et al. 2018a). As an alternative, the authors of this review suggest it is more feasible to change the mindset from using MNFC to improve the strength properties of commercially available papers to using MNFC to produce a lighter-weight version of these papers (keeping all the properties consistent to what is currently on the market) by reducing the overall fiber content. This is in agreement with the trend in papermaking of reducing fiber (Retulainen and Nieminen 1996) and, at the same time, should allow for a more rapid introduction of the MNFC into the industry.

\section{Case Study: Reducing the Grammage of Unrefined Hardwood Chemical Fiber Sheets}

This section intends to demonstrate the potential savings obtained from the grammage reduction driven by the addition of NFC to paper sheets having a target tensile strength. The analysis is based on experimental data presented by Hamann (2011), who studied the effect of grammage reduction for sheets prepared with unrefined hardwood chemical pulp with $10 \%$ addition of NFC, as shown in Fig. 8. In a parallel study, the author tested the effect of different NFC loads on the tensile strength of $60 \mathrm{~g} / \mathrm{m}^{2}$ sheets. These results, indicated by the colored dots in Fig. 8, were added to the original chart.

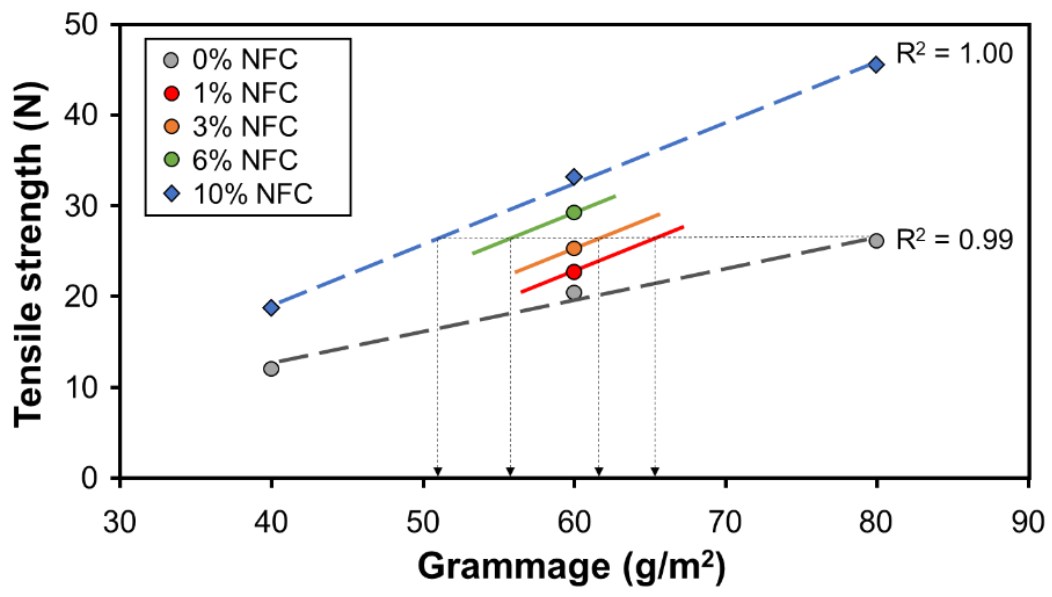

Fig. 8. Grammage reduction is driven by the addition of NFC. Note that the same tensile strength is reached by using different combinations of grammage and NFC load (adapted from Hamann 2011)

For the analysis, an $80 \mathrm{~g} / \mathrm{m}^{2}$ sheet without NFC, with a tensile strength of $26.2 \mathrm{~N}$, was selected as the base case. The authors found a strong linear correlation between the grammage and the tensile strength with and without NFC $\left(\mathrm{R}^{2}\right.$ equals to 1.00 and 0.99 , respectively). Therefore, it was assumed that there is not a strong dependence between the rate of change in the tensile strength per grammage unit and the NFC load used. Considering the slope of the dataset with $10 \%$ NFC, the tensile strength was extrapolated 
for each NFC load in the $60 \mathrm{~g} / \mathrm{m}^{2}$ sheet to reach a value of $26.2 \mathrm{~N}$. As a result, it was possible to obtain paper sheets with different grammages and NFC loads exhibiting the same tensile strength value. The results are shown in Fig. 8.

Figure 9 shows potential cost reduction driven by the addition of NFC for both recycled and virgin fibers. The grammage reduction was calculated considering the amount of fiber that is possible to reduce for the different NFC-grammage combinations obtained from Fig. 8. The cost reduction was assessed as the difference between the US dollars per metric ton of dry pulp saved and the US dollars associated with the NFC load required to deliver the target tensile strength value. Two cost references (low and high) were selected to evaluate the sensitivity of the fiber cost on the cost reduction. These values, USD 820 and USD 1,100 per ton of fiber respectively, were taken from the RISI database and correspond to the lowest and highest cost of northern and southern mixed bleached hardwood kraft (Canadian/US) between December 2016 and April 2018 (Fastmarkets RISI 2017). The cost per dry ton of NFC considered was USD 1,493. This value corresponds to an MNFC manufacturing facility that is co-located within a mill that produces northern bleached softwood kraft (NBSK) pulp (De Assis et al. 2017).

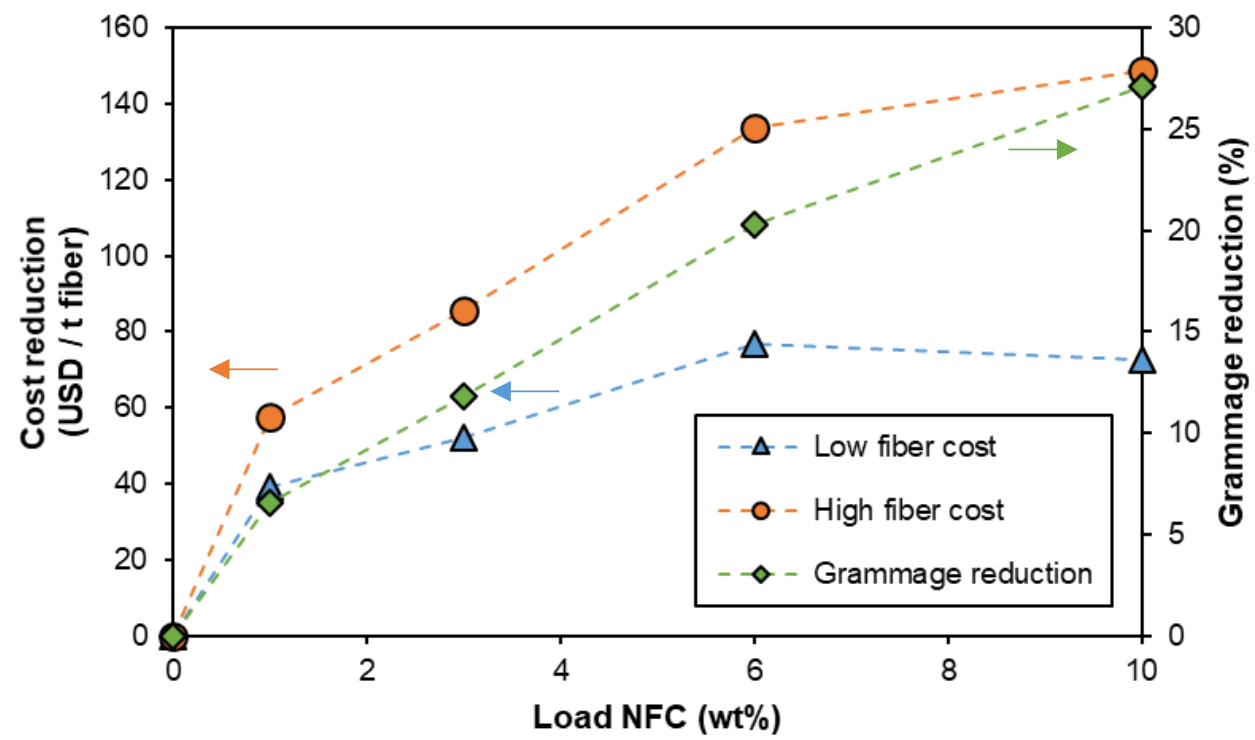

Fig. 9. Potential cost reduction per ton of fiber driven by the addition of NFC. The gray dotted line indicates the \% of grammage reduction that can be obtained by adding the indicated NFC load. The orange and blue dotted line show how such cost reduction would translate in USD savings per ton of fiber depending on the fiber cost. Low and high fiber cost are estimated to be USD 820 and USD 1,100 per ton of fiber respectively. The cost per dry ton of NFC considered was USD 1,493 based on the study published by De Assis et al. (2017)

Figure 10 shows that loads of NFC as low as $1 \mathrm{wt} \%$ already drive cost reduction. The CNF load that maximizes the cost reduction depends on the cost of the fiber used for the furnish preparation. For the low fiber cost, this load is around $6 \mathrm{wt} \%$, whereas for high fiber cost there is no maximum within the range studied. As the cost of the raw material increases, savings due to cost reduction are higher. In this study, cost reduction can be as high as USD 77 and USD 149 per ton of fiber for low and high fiber cost, respectively. Cheaper fibers, i.e., recycled fiber, will have a more restricted range of operation before the addition of MNFC becomes economically infeasible. 
Although the numbers shown in this study seem promising, additional aspects need to be considered before such an operation can be scaled-up. First, this analysis is based only on the tensile strength. A reduction in the grammage deteriorates almost all paper properties, including those indexed by the basis weight (Retulainen and Nieminen 1996). Thus, an integrated analysis considering the lowest acceptable basis weight according to the paper grade produced needs to be considered. Second, Hamann (2011) reported a 50\% retention of NFC, and no retention aid was introduced in the paper furnish to improve this value. If retention is less than $50 \%$, using up to $6 \mathrm{wt} \%$ NFC might cause problems in the runnability of the paper machine. On top of a negative impact on dewatering, a potential build-up of NFC in the closed loop of the paper machine could increase the viscosity of the recirculating water, making the operation impractical. At the same time, filling of wet-press felts in the paper machine with unretained NFC may also represent an aspect of potential concern due to its difficult removal by conventional treatments. This highlights the need for carrying out an integrated analysis to study the feasibility of the use of MNFC to reduce the fiber content.

\section{Determining the Trade-off Between the Degree of Fibrillation and Load when Using MNFC as a Paper Strength Additive}

From the previous discussion, one can expect there to be a fibrillation threshold (optimum degree of fibrillation) from which any further mechanical treatment does not translate into a significant increase in the mechanical properties of the paper. Moreover, a trade-off between the degree of fibrillation and the nanocellulose load required to achieve a target tensile strength value has been reported in the literature (Delgado-Aguilar et al. 2015; Johnson et al. 2016). From this situation, two possible scenarios can be developed: (i) a small load of MNFC is required at the expense of a high degree of fibrillation (small particle size) or (ii) a small degree of fibrillation (high particle size) is required at the expense of a high load of MNFC. In this sense, when using MNFC as a paper strength additive, the question of what the most profitable scenario is arises. This highlights the importance of understanding the role of the particle size (micro versus nano) and degree of fibrillation in the nanocellulose performance.

\section{Case Study: Increasing in 10\% the Tensile Strength of a Hardwood Sheet Using Softwood CNF}

This section intends to estimate a feasible combination of the particle size and the load of CNF required to reach a target paper strength. The analysis is based on a technoeconomic assessment using experimental data presented by Johnson et al. (2016) that is shown in Table 4. In that work, the authors determined the load required to reach a target tensile value of $10 \%$ above that of a hardwood base sheet by using CNF having different fines content. As a practical approach, the fines content was correlated with the particle size using SEM, e.g., a CNF slurry at $90 \%$ fines has dimensions at the nanoscale. Measurements of the particle size for each fines content are not provided in the study. However, it is inferred that for a low fines content, a material with a width at the microscale predominates and the width moves towards the nanoscale as the fines content increases.

The energy required to reach each specific fines content was used as an input in the manufacturing cost model for CNF proposed by De Assis et al. (2017). This model is based on process data from a CNF pilot facility at the University of Maine, the same facility where the experimental data used for this analysis were collected. Therefore, the 
manufacturing cost associated with each fines content was estimated, considering one ton of dry CNF as the basis. The results are presented in Table 4.

Table 4. CNF Load Required to Increase the Tensile Value $10 \%$ Above of a Hardwood Base Sheet

\begin{tabular}{|c|c|c|c|}
\hline $\begin{array}{c}\text { Fines in CNF } \\
\text { (\%) }\end{array}$ & $\begin{array}{c}\text { CNF Load } \\
\text { (\%) }\end{array}$ & $\begin{array}{c}\text { Tensile index } \\
\text { (N.m/g) }\end{array}$ & $\begin{array}{c}\text { Manufacturing Cost }^{2} \\
\text { (USD/t CNF Dry) }\end{array}$ \\
\hline \multicolumn{2}{|c|}{ Hardwood base sheet } & 54.0 & - \\
\hline 50 & 6.1 & 59.4 & 1,326 \\
\hline 65 & 5.0 & 59.8 & 1,366 \\
\hline 75 & 3.3 & 59.4 & 1,394 \\
\hline 85 & 2.7 & 59.4 & 1,425 \\
\hline 95 & 3.1 & 59.4 & 1,493 \\
\hline
\end{tabular}

Note: ${ }^{1}$ Tensile index values from Johnson et al. (2016); ${ }^{2}$ Cost calculated using manufacturing cost model for CNF proposed by De Assis et al. (2017)

Figure 10 shows the CNF load cost per ton of finished product depending on the fines content in the CNF used.

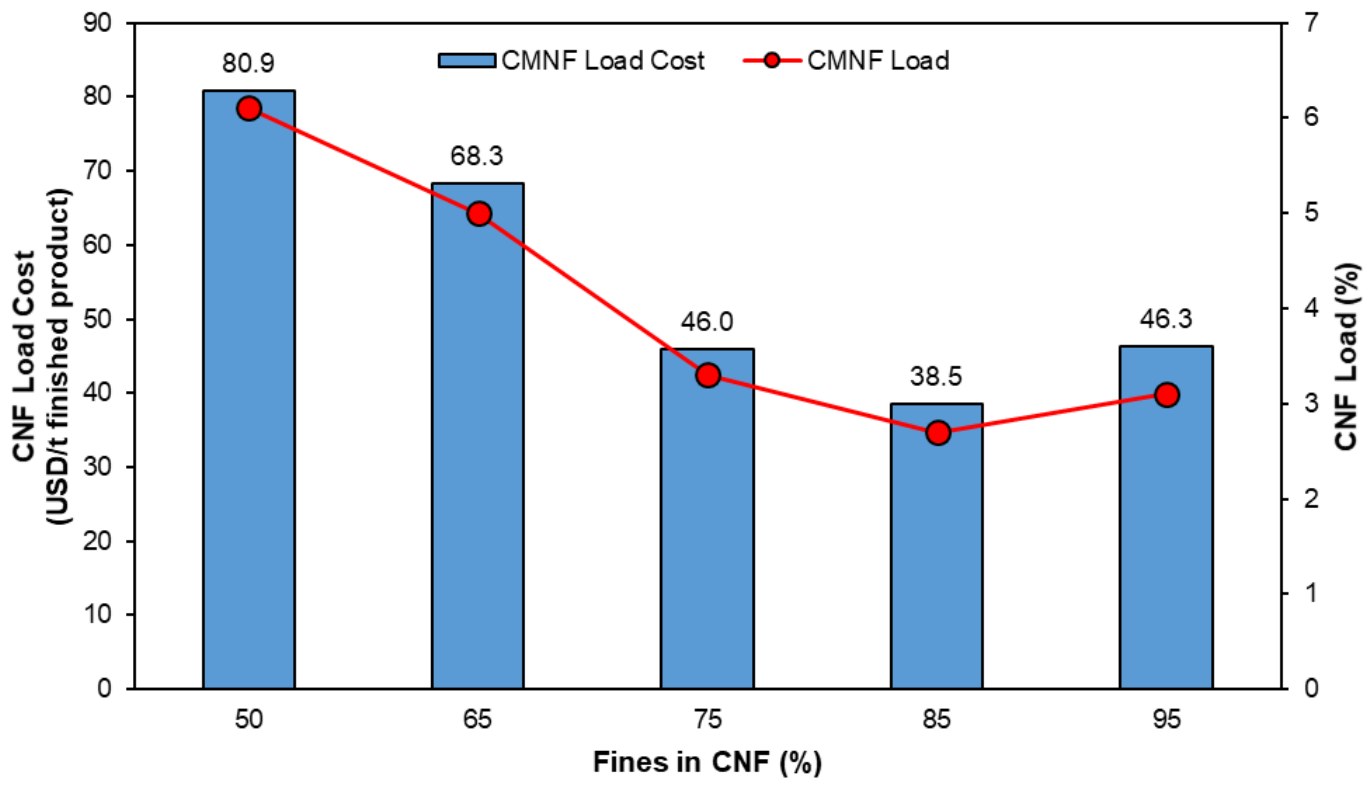

Fig. 10. Load cost required to achieve a $10 \%$ increase in the tensile index of a hardwood base sheet by using softwood CNF with different fines content. As the fines content increases, the CNF load decreases and levels off after a $75 \%$ fines content is reached.

As the fines content increases, the CNF load required to increase the tensile index $10 \%$ decreases and there is no significant difference in the required load after $75 \%$ fines content is reached. These lower concentrations used in conjunction with the more fibrillated CNF (fines content $>75 \%$ ), offsets the high manufacturing cost. For instance, when going from $50 \%$ to $75 \%$ fines, the CNF load cost is reduced by approximately $43 \%$. Based on the techno-economic assessment performed, it is possible to state that moving 
towards the nanoscale is economically justifiable, although, the question arises as to how far one should go.

Starting from $75 \%$ fines content, the change of the load cost is less sensitive to the fines content. This is because energy consumption tends to level off as the fines content increases. A drop of 3\% in the $95 \%$ fines CNF load (from 3.10\% down to 3.01\%), which would be considered as a favorable scenario, would decrease the load cost approximately $2.3 \%$ with respect to the $75 \%$ fines CNF load (from USD 46.3 to USD 44.9 per ton of finished product). This small change might make the producer skeptical about whether it is worthwhile to pursue high levels of fibrillation. Therefore, other variables than just the cost component must be considered in the decision-making process. As discussed elsewhere in this review, there are challenges related to retention, slow dewatering, and drying that need to be to overcome when using $\mathrm{CNF}$ as a paper additive which are more likely to justify the use of CNF at a lower fines content.

\section{OTHER ALTERNATIVES FOR FIBER REDUCTION}

\section{Dry Strength Additives}

Dry strength additives are commonly used in the paper industry as a way to maintain strength properties with less refining or with lower quality fibers (Hubbe 2007a). Figure 11 shows how dry strength additives can be used to reduce the amount of fiber required to produce a specific strength target.

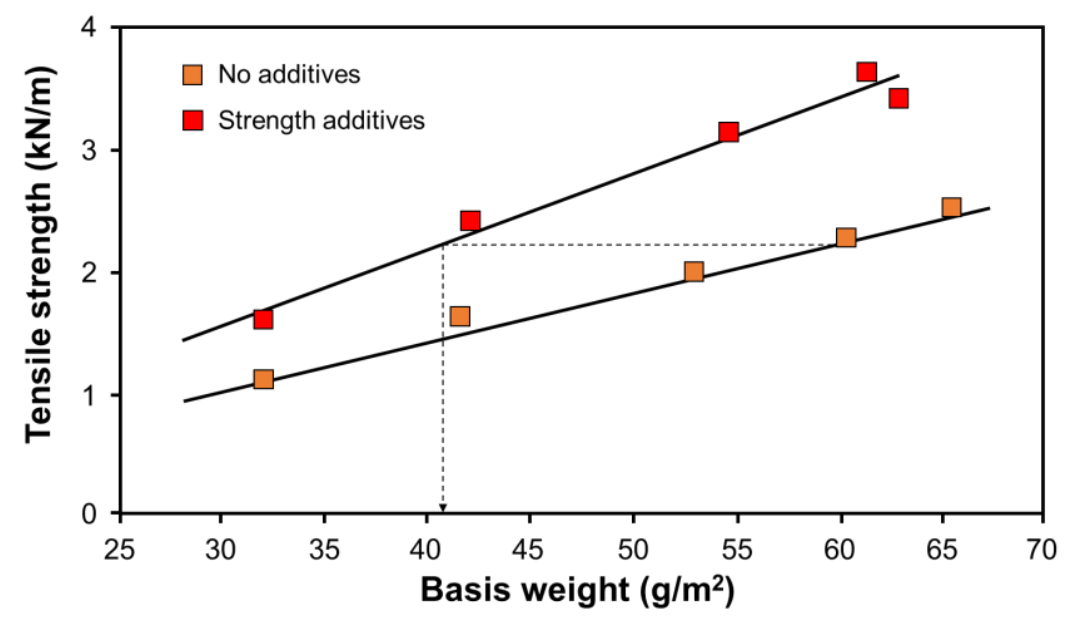

Fig. 11. The use of $1.2 \%$ cationic potato starch and $0.4 \%$ carboxymethyl cellulose produced a 42 $\mathrm{g} / \mathrm{m}^{2}$ sheet with the same tensile strength as a $60 \mathrm{~g} / \mathrm{m}^{2}$ sheet with no additives (adapted from Retulainen and Nieminen 1996)

A general characteristic of dry-strength additives, such as cationic starch, is that strength gains may be cost-effective only up to a modest improvement in properties. Limitations in achievable strength gains are often related to maximum amounts of the polymers that can be absorbed by the fiber surfaces. Many of the paper machine systems that might be considered as candidates for MNFC addition will already be using various dry strength chemical additives at optimized levels, together with optimized levels of refining of the fibers. 
A characteristic of using dry strength additives is that the sheet thickness is often reduced compared to the case where no dry strength additives are present; in principle, this might negatively impact properties such as bending stiffness and bulk (Retulainen and Nieminen 1996). The latter are important components of packaging and tissue grades, respectively. However, if the additive makes it possible to maintain strength at a lower degree of refining, then the bulky nature of less-refined fibers might yield the opposite overall effect. Because dry strength additives, with particular reference to cationic starch and various acrylamide-based strength additives, are likely to remain used in applications where strength might allow basis weight reductions, it is very important that future research work includes evaluations of systems involving various combinations of MNFC and drystrength chemicals, working together.

\section{Fines-enriched Pulp}

Fines-enriched pulp is produced using a high intensity, multiple pass refining operation in conjunction with a fractionation process. In laboratory experiments, finesenriched pulp has been shown to be twice as effective as glue pulp (highly refined kraft pulp used as a plybond enhancer) in terms of increasing multi-ply board strength, but it negatively impacts sheet bulk (Björk et al. 2017). The properties imparted on the sheet by the fines is heavily dependent on the fiber raw material (Fischer et al. 2017). Typically, in a furnish with a high fines content, the fines have been generated by excessively refining the fiber furnish, which breaks off more portions of the fiber layers, and even by fiber cutting in extreme cases. Because the fines Björk et al. (2017) used to enrich the pulp were generated during a separate refining process, this removes the negative impacts on paper properties associated with fiber cutting in the furnish. Despite the negative effects of having too many fines in the sheet, some fines must be present in the sheet to help with fiber-fiber bonding and ultimately the strength of the sheet. Fines-enriched pulp could be an alternative to MNFC; however, fines-enriched pulp produces a weaker, more porous, rougher sheet of paper than in the case of adding MNFC to the furnish (Fischer et al. 2017), which may not be desirable for some applications.

\section{CONCLUDING REMARKS}

Based on the literature reviewed, the authors have acknowledged the potential to create value in the paper industry by introducing MNFC as a driver for cost reduction, along with the potential challenges associated with said strategy. The high manufacturing costs associated with the increase in fiber prices represent an opportunity for cost savings through the reduction of fiber content in paper products. Standards for paper strength are already established, and customers are not willing to pay a premium to have a super strong product. Therefore, instead of using MNFC as a paper strength additive, the real business opportunity may involve the use of MNFC to reduce the fiber content while delivering the strength commercially required.

The fiber price for the furnish preparation is what determines the optimum amount of MNFC to be used to maximize the cost reduction. For the techno-economic assessment conducted in this review, the tensile strength was the only property considered as a reference. Further research to evaluate the role of MNFC as a driver for fiber reduction in low grammage papers, e.g., tissue and towel, and the impact that this reduction might have 
on other physical properties, e.g., water absorbency, bulk, and softness, needs to be performed.

Likewise, the use of polyelectrolytes in combination with the MNFC represents an alternative to further increase the cost reduction. For instance, an increase in MNFC retention due to the use of polyelectrolytes could allow a reduction in the load required to achieve a target tensile strength at a given grammage. At the same time, the development of potential polyelectrolyte/MNFC synergies could also be beneficial in the task of reducing fiber.

The use of MNFC as a paper strength additive also requires a feasible combination of the particle size and load in the paper furnish. It was found that lower concentrations of softwood CNF associated with high fines content (high degree of fibrillation) outweigh the higher manufacturing costs. From an economic point of view, this justifies using nanofibrillated cellulose instead of microfibrillated cellulose; however, operational challenges related to retention, slow dewatering, and drying of the nanocellulose might also need to be considered to select one type or another.

Finally, another important aspect to bring into the discussion is the fiber source used for the MNFC production. Thus far, energy processing cost had been noted as an issue in the manufacturing of MNFC; however, a recent study showed that the fiber source is the major cost driver. The cost of the cellulosic fiber typically represents more than $60 \%$ of the total manufacturing cost (De Assis et al. 2017). Johnson et al. (2016) stated that for high fines content $(>95 \%)$ both hardwood and softwood CNF show an equivalent performance when added into a paper furnish. Therefore, the most profitable alternative would consist in using the MNFC manufactured with the pulp fiber with the lower price; however, this might not be true for MNFC with an intermediate fines content. The latter highlights the need to conduct research considering several fiber sources and fines contents in combination with different polyelectrolytes. The authors believe that, on top of the gain in the paper strength, the key point to select the nanoscale and the specific fiber source used for the MNFC production will depend on additional improvements in other physical properties powered by the nano-feature that could potentially add extra value to the paper grade produced.

\section{REFERENCES CITED}

Abdul Khalil, H. P. S., Bhat, A. H., and Ireana Yusra, A. F. (2012). "Green composites from sustainable cellulose nanofibrils: A review," Carbohydrate Polymers 87(2), 963-979. DOI: 10.1016/j.carbpol.2011.08.078

Abdul Khalil, H. P. S., Davoudpour, Y., Islam, M. N., Mustapha, A., Sudesh, K., Dungani, R., and Jawaid, M. (2014). "Production and modification of nanofibrillated cellulose using various mechanical processes: A review," Carbohydrate Polymers 99, 649-665. DOI: 10.1016/j.carbpol.2013.08.069

Afra, E., Yousefi, H., Hadilam, M. M., and Nishino, T. (2013). "Comparative effect of mechanical beating and nanofibrillation of cellulose on paper properties made from bagasse and softwood pulps," Carbohydrate Polymers 97(2), 725-730. DOI: 10.1016/j.carbpol.2013.05.032

Ahola, S., Österberg, M., and Laine, J. (2008). "Cellulose nanofibrils - Adsorption with poly(amideamine) epichlorohydrin studied by QCM-D and application as a paper strength additive," Cellulose 15(2), 303-314. DOI: 10.1007/s10570-007-9167-3 
Alcalá, M., González, I., Boufi, S., Vilaseca, F., and Mutjé, P. (2013). “All-cellulose composites from unbleached hardwood kraft pulp reinforced with nanofibrillated cellulose," Cellulose 20(6), 2909-2921. DOI: 10.1007/s10570-013-0085-2

Ankerfors, M., Duker, E., and Lindström, T. (2013). "Topo-chemical modification of fibres by grafting of carboxymethyl cellulose in pilot scale," Nordic Pulp \& Paper Research Journal 28(1), 6-14. DOI: 10.3183/npprj-2013-28-01-p006-014

De Assis, C. A., Iglesias, M. C., Bilodeau, M., Johnson, D., Phillips, R., Peresin, M. S., Bilek, E. M., Rojas, O. J., Venditti, R., and Gonzalez, R. (2017). "Cellulose microand nanofibrils (CMNF) manufacturing - financial and risk assessment," Biofuels, Bioproducts and Biorefining 12(6), 251-264. DOI: 10.1002/bbb.1835

De Assis, T., Reisinger, L., Dasmohapatra, S., Pawlak, J., Jameel, H., Pal, L., Kavalew, D., and Gonzalez, R. (2018a). "Performance and sustainability vs. the shelf price of tissue paper kitchen towels," BioResources 13(3), 6868-6892. DOI: 10.15376/biores.13.2.DeAssis

De Assis, T., Reisinger, L. W., Pal, L., Pawlak, J., Jameel, H., and Gonzalez, R. W. (2018b). "Understanding the effect of machine technology and cellulosic fibers on tissue properties - A review," BioResources 13(2), 4593-4629. DOI: 10.15376/biores.13.2.DeAssis

Balea, A., Sanchez-Salvador, J. L., Monte, M. C., Merayo, N., Negro, C., and Blanco, A. (2019). "In situ production and application of cellulose nanofibers to improve recycled paper production," Molecules 24(9), 1800. DOI:

10.3390/molecules24091800

Balea, A., Blanco, Á., Monte, M. C., Merayo, N., and Negro, C. (2016). "Effect of bleached eucalyptus and pine cellulose nanofibers on the physico-mechanical properties of cartonboard," BioResources 11(4), 8123-8138. DOI:

10.15376/biores.11.4.8123-8138

Björk, E., Vomhoff, H., and Bouveng, M. (2017). "Usage of fines-enriched pulp to increase strength in CTMP," in: Paper Conference and Trade Show: Renew, Rethink, Redefine the Future, PaperCon 2017, Minneapolis, MN, USA, pp. 1607-1631.

Boufi, S., González, I., Delgado-Aguilar, M., Tarrès, Q., Pèlach, M. À., and Mutjé, P. (2016). "Nanofibrillated cellulose as an additive in papermaking process: A review," Carbohydrate Polymers 154, 151-166. DOI: 10.1016/j.carbpol.2016.07.117

Brodin, F. W., Gregersen, Ø. W., and Syverud, K. (2014). "Cellulose nanofibrils: Challenges and possibilities as a paper additive or coating material - A review," Nordic Pulp \& Paper Research Journal 29(1), 156-166. DOI: 10.3183/npprj-201429-01-p156-166

Campano, C., Merayo, N., Balea, A., Tarrés, Q., Delgado-Aguilar, M., Mutjé, P., Negro, C., and Blanco, Á. (2018). "Mechanical and chemical dispersion of nanocelluloses to improve their reinforcing effect on recycled paper," Cellulose 25(1), 269-280. DOI: $10.1007 / \mathrm{s} 10570-017-1552-y$

Charani, R. P., Dehghani-Firouzabadi, M., Afra, E., Blademo, Å., Naderi, A., and Lindström, T. (2013). "Production of microfibrillated cellulose from unbleached kraft pulp of kenaf and Scotch pine and its effect on the properties of hardwood kraft: Microfibrillated cellulose paper," Cellulose 20(5), 2559-2567. DOI: 10.1007/s10570-013-9998-z

Charreau, H. L., Foresti, M., and Vazquez, A. (2012). 'Nanocellulose patents trends: A comprehensive review on patents on cellulose nanocrystals, microfibrillated and bacterial cellulose," Recent Patents on Nanotechnology 7(1), 56-80. DOI: 


\section{$10.2174 / 1872210511307010056$}

Chinga-Carrasco, G. (2011). "Cellulose fibres, nanofibrils and microfibrils: The morphological sequence of MFC components from a plant physiology and fibre technology point of view," Nanoscale Research Letters 6(1), 417. DOI: $10.1186 / 1556-276 \mathrm{X}-6-417$

CSA Z5100-14 (2014). "Cellulosic nanomaterials - Test methods for characterization," Canadian Standards Association, Toronto, Canada.

Delgado-Aguilar, M., González, I., Tarrés, Q., Alcalà, M., Pèlach, M. À., and Mutjé, P. (2015). "Approaching a low-cost production of cellulose nanofibers for papermaking applications," BioResources 10(3), 5345-5355. DOI:

10.15376/biores.10.3.5345-5355

Dufresne, A. (2013). "Nanocellulose: A new ageless bionanomaterial," Materials Today 16(6), 220-227. DOI: 10.1016/j.mattod.2013.06.004

Eriksen, Ø., Syverud, K., and Gregersen, Ø. (2008). "The use of microfibrillated cellulose produced from kraft pulp as strength enhancer in TMP paper," Nordic Pulp \& Paper Research Journal 23(3), 299-304. DOI: 10.3183/npprj-2008-23-03-p299-304

Fastmarkets RISI (2017). "Quartely news and analysis of global tissue markets (Q1)," World Tissue Business Monitor, retrieved from (http://www.risiinfo.com), Accessed 2 Oct 2017.

Fastmarkets RISI (2017). "Prices for pulp, recovered paper, paper, packaging, timber, wood products, and nonwovens markets," Fastmarkets RISI, retrieved from (http://www.risiinfo.com), Accesed 1 Dec 2017.

Ferrer, A., Quintana, E., Filpponen, I., Solala, I., Vidal, T., Rodríguez, A., Laine, J., and Rojas, O. J. (2012). "Effect of residual lignin and heteropolysaccharides in nanofibrillar cellulose and nanopaper from wood fibers," Cellulose 19(6), 21792193. DOI: $10.1007 / \mathrm{s} 10570-012-9788-\mathrm{Z}$

Fischer, W. J., Mayr, M., Spirk, S., Reishofer, D., Jagiello, L. A., Schmiedt, R., Colson, J., Zankel, A., and Bauer, W. (2017). "Pulp fines-characterization, sheet formation, and comparison to microfibrillated cellulose," Polymers 9(8), Article Number 366. DOI: $10.3390 /$ polym9080366

French, A. D. (2017). "Glucose, not cellobiose, is the repeating unit of cellulose and why that is important," Cellulose 24(11), 4605-4609. DOI: 10.1007/s10570-017-1450-3

González, I., Alcalà, M., Chinga-Carrasco, G., Vilaseca, F., Boufi, S., and Mutjé, P. (2014). "From paper to nanopaper: Evolution of mechanical and physical properties," Cellulose 21(4), 2599-2609. DOI: 10.1007/s10570-014-0341-0

González, I., Boufi, S., Pélach, M. A., Alcalá, M., Vilaseca, F., and Mutjé, P. (2012). "Nanofibrillated cellulose as paper additive in eucalyptus pulps," BioResources 7(4), 5167-5180. DOI: 10.15376/biores.7.4.5167-5180

González, I., Vilaseca, F., Alcalá, M., Pèlach, M. A., Boufi, S., and Mutjé, P. (2013). "Effect of the combination of biobeating and NFC on the physico-mechanical properties of paper," Cellulose 20(3), 1425-1435. DOI: 10.1007/s10570-013-9927-1

Goto, S., Noda, T., Yuzawa, C., and Limori, T. (2014). "Cellulose-based fibrous material," U.S. Patent No. 20090065164.

Habibi, Y., Lucia, L. A., and Rojas, O. J. (2010). "Cellulose nanocrystals: Chemistry, self-assembly, and applications," Chemical Reviews 110(6), 3479-3500. DOI: $10.1021 / \mathrm{cr} 900339 \mathrm{w}$

Hakeem, K. R., Jawaid, M., and Alothman, O. Y. (2015). Agricultural Biomass Based Potential Materials, K. R. Hakeem, M. Jawaid, and O. Y. Alothman (eds.), Springer 
International Publishing, Basel, Switzerland. DOI: 10.1007/978-3-319-13847-3

Hamann, L. (2011). "Wet-end and bulk applications of NFC," in: SUNPAP Workshop, Espoo, Finland.

He, M., Yang, G., Cho, B. U., Lee, Y. K., and Won, J. M. (2017). "Effects of addition method and fibrillation degree of cellulose nanofibrils on furnish drainability and paper properties," Cellulose 24(12), 5657-5669. DOI: 10.1007/s10570-017-1495-3

Heiskanen, I., Ruhoniemi, N., Lepisto, V., Jouni, T., Tapio, S., Jurvanen, T., and Suhonen, P. (2016). "Wet laid sheet material of a microfibrillated material composition," U.S. Patent No. US9518364B2.

Herrera, M., Thitiwutthisakul, K., Yang, X., Rujitanaroj, P., Rojas, R., and Berglund, L. (2018). "Preparation and evaluation of high-lignin content cellulose nanofibrils from eucalyptus pulp," Cellulose 25(5), 3121-3133. DOI: 10.1007/s10570-018-1764-9

Hollertz, R., Durán, V. L., Larsson, P. A., and Wågberg, L. (2017). “Chemically modified cellulose micro- and nanofibrils as paper-strength additives," Cellulose 24(9), 3883-3899. DOI: 10.1007/s10570-017-1387-6

Hubbe, M. A. (2019). "Nanocellulose, cationic starch and paper strength," Appita Journal 72(2), 82.

Hubbe, M. A. (2007a). "Bonding between cellulosic fibers in the absence and presence of dry strength agents - A review," BioResources 1(2), 281-318.

Hubbe, M. A. (2007b). "Flocculation and redispersion of cellulosic fiber suspensions: A review of effects of hydrodynamic shear and polyelectrolytes," BioResources 2(2), 296-331. DOI: 10.15376/biores.2.2.196-331

Ilyas, R. A., Sapuan, S. M., Sanyang, M. L., Ishak, M. R., and Zainudin, E. S. (2018). "Nanocrystalline cellulose as reinforcement for polymeric matrix nanocomposites and its potential applications: A review," Current Analytical Chemistry 14(3), 203225. DOI: $10.2174 / 1573411013666171003155624$

Imani, M., Ghasemian, A., Dehghani-Firouzabadi, M. R., Afra, E., Gane, P. A., and Rojas, O. J. (2019a). "Nano-lignocellulose from recycled fibres in coatings from aqueous and ethanolic media: Effect of residual lignin on wetting and offset printing quality," Nordic Pulp \& Paper Research Journal 34(2), 200-210. DOI: 10.1515/npprj-2018-0053

Imani, M., Ghasemian, A., Dehghani-Firouzabadi, M. R., Afra, E., Borghei, M., Johansson, L. S., Gane, P. A., and Rojas, O. J. (2019b). "Coupling nanofibril lateral size and residual lignin to tailor the properties of lignocellulose films," Advanced Materials Interfaces 6(19), Article ID 1900770. DOI: 10.1002/admi.201900770

Islam, M. T., Alam, M. M., Patrucco, A., Montarsolo, A., and Zoccola, M. (2014). "Preparation of nanocellulose: A review," AATCC Journal of Research 1(5), 17-23. DOI: 10.14504/ajr.1.5.3

ISO/TC6-TG1 (1947). "Paper, boards and pulps - Cellulosic nanomaterials," International Organization for Standardization, Geneva, Switzerland.

ISO/TC 229 (2005). "Nanotechnologies," International Organization for Standardization, Geneva, Switzerland.

Isogai, A. (2013). "Wood nanocelluloses: Fundamentals and applications as new biobased nanomaterials," Journal of Wood Science 59(6), 449-459. DOI: 10.1007/s10086-013-1365-z

Iwamoto, S., Abe, K., and Yano, H. (2008). "The effect of hemicelluloses on wood pulp nanofibrillation and nanofiber network characteristics," Biomacromolecules 9(3), 1022-1026. DOI: 10.1021/bm701157n 
Johnson, D. A., Paradis, M. A., Bilodeau, M., Crossley, B., Foulger, M., and Gélinas, P. (2016). "Effects of cellulosic nanofibrils on papermaking properties of fine papers," TAPPI Journal 15(6), 395-402.

Jonoobi, M., Oladi, R., Davoudpour, Y., Oksman, K., Dufresne, A., Hamzeh, Y., and Davoodi, R. (2015). "Different preparation methods and properties of nanostructured cellulose from various natural resources and residues: A review," Cellulose 22(2), 935-969. DOI: 10.1007/s10570-015-0551-0

Kasmani, J., and Samariha, A. (2019). "Effect of nano-cellulose on the improvement of the properties of paper newspaper produced from chemi-mechanical pulping," BioResources 14(4), 8935-8949. DOI: 10.15376/biores.14.4.8935-8949

Klemm, D., Kramer, F., Moritz, S., Lindström, T., Ankerfors, M., Gray, D., and Dorris, A. (2011). "Nanocelluloses: A new family of nature-based materials," Angewandte Chemie - International Edition 50(24), 5438-5466. DOI: 10.1002/anie.201001273

Konstantinova, S. A., Semkina, L. I., Anikushin, B. M., Zuikov, A. A., Glagoleva, O. F., and Vinokurov, V. A. (2019). "Natural polymer additives for strengthening packaging materials," Chemistry and Technology of Fuels and Oils 55(5), 561-567. DOI: $10.1007 / \mathrm{s} 10553-019-01067-9$

Kullander, J., Nilsson, L., and Barbier, C. (2012). "Evaluation of furnishes for tissue manufacturing; suction box dewatering and paper testing," Nordic Pulp \& Paper Research Journal 27(1), 143-150. DOI: 10.3183/npprj-2012-27-01-p143-150

Lahtinen, P., Liukkonen, S., Pere, J., Sneck, A., and Kangas, H. (2014). “A comparative study of fibrillated fibers from different mechanical and chemical pulps," BioResources 9(2), 2115-2127. DOI: 10.15376/biores.9.2.2115-2127

Lavoine, N., Desloges, I., Dufresne, A., and Bras, J. (2012). "Microfibrillated cellulose Its barrier properties and applications in cellulosic materials: A review," Carbohydrate Polymers 90(2), 735-764. DOI: 10.1016/j.carbpol.2012.05.026

Lu, Z., An, X., Zhang, H., Liu, L., Dai, H., Cao, H., Lu, B. and Liu, H. (2020). “Cationic cellulose nano-fibers (CCNF) as versatile flocculants of wood pulp for high wet web performance," Carbohydrate Polymers 229, 115434. DOI:

10.1016/j.carbpol.2019.115434

Lu, Z., An, X., Zhang, H., Guan, M., Liu, J., Sun, Y., Nie, S., Cao, H., Lu, B. and Liu, H. (2019). "Study on the wet-web strength and pressability of paper sheet during the press process with the addition of nano-fibrillated cellulose (NFC)," Carbohydrate Polymers 210, 332-338. DOI: 10.1016/j.carbpol.2019.01.083

Madani, A., Olson, J. A., Kiiskinen, H., and Martinez, D. M. (2011). "Fractionation of microfibrillated cellulose and its effects on tensile index," Nordic Pulp \& Paper Research Journal 26(3), 744-751. DOI: 10.3183/npprj-2011-26-03-p306-311

Manninen, M., Isko, K., Happonen, J., and Paltakari, J. (2011). "The effect of microfibrillated cellulose addition on drying shrinkage and dimensional stability of wood-free paper," Nordic Pulp \& Paper Research Journal 26(3), 297-305. DOI: 10.3183/npprj-2011-26-03-p297-305

Merayo, N., Balea, A., de la Fuente, E., Blanco, Á., and Negro, C. (2017a). "Interactions between cellulose nanofibers and retention systems in flocculation of recycled fibers," Cellulose 24(2), 677-692. DOI: 10.1007/s10570-016-1138-0

Merayo, N., Balea, A., De la Fuente, E., Blanco, Á., and Negro, C. (2017b). "Synergies between cellulose nanofibers and retention additives to improve recycled paper properties and the drainage process, Cellulose 24(7), 2987-3000. DOI:

10.1007/s10570-017-1302-1 
Moon, R. J., Martini, A., Nairn, J., Simonsen, J., and Youngblood, J. (2011). "Cellulose nanomaterials review: structure, properties and nanocomposites," Chemical Society Reviews 40, 3941-3994. DOI: 10.1039/c0cs00108b

Morales, L. O., Iakovlev, M., Martin-Sampedro, R., Rahikainen, J. L., Laine, J., Van Heiningen, A., and Rojas, O. J. (2014). "Effects of residual lignin and heteropolysaccharides on the bioconversion of softwood lignocellulose nanofibrils obtained by $\mathrm{SO}_{2}$-ethanol-water fractionation," Bioresource Technology 161, 55-62. DOI: 10.1016/j.biortech.2014.03.025

Nakagaito, A. N., Iwamoto, S., and Yano, H. (2005). "Bacterial cellulose: The ultimate nano-scalar cellulose morphology for the production of high-strength composites," Applied Physics A: Materials Science and Processing 80(1), 93-97. DOI: 10.1007/s00339-004-2932-3

Nechyporchuk, O., Belgacem, M. N., and Bras, J. (2016). "Production of cellulose nanofibrils: A review of recent advances," Industrial Crops and Products 93, 2-25. DOI: 10.1016/j.indcrop.2016.02.016

Nechyporchuk, O., Pignon, F., and Belgacem, M. N. (2014). "Morphological properties of nanofibrillated cellulose produced using wet grinding as an ultimate fibrillation process," Journal of Materials Science 50(2), 531-541. DOI: 10.1007/s10853-0148609-1

Osong, S. H., Norgren, S., and Engstrand, P. (2014). "Paper strength improvement by inclusion of nano-ligno- cellulose to chemi-thermomechanical pulp," Nordic Pulp \& Paper Research Journal 29(2), 309-316. DOI: 10.3183/npprj-2014-29-02-p309-316

Osong, S. H., Norgren, S., and Engstrand, P. (2016). "Processing of wood-based microfibrillated cellulose and nanofibrillated cellulose, and applications relating to papermaking: A review," Cellulose 23(1), 93-123. DOI: 10.1007/s10570-015-0798-5

Page, D. H. (1969). "A theory for the tensile strength of paper," TAPPI Journal 52(4), 674-681.

Potulski, D. C., De Muniz, G. I. B., Klock, U., and De Andrade, A. S. (2014). "Influência da incorporação de celulose microfibrilada nas propriedades de resistência mecânicas do papel [Influence of the incorporation of microfibrillated cellulose on the mechanical strength properties of paper]," Scientia Forestalis 40(103), 345-351.

Retulainen, E., and Nieminen, K. (1996). "Fiber properties as control variables in papermaking? Part 2. Strengthening interfiber bonds and reducing grammage," Paperi ja Puu 78(5), 305-312.

Rice, M. C., Pal, L., Gonzalez, R., and Hubbe, M. A. (2018). "Wet-end addition of nanofibrillated cellulose pretreated with cationic starch to achieve paper strength with less refining and higher bulk," TAPPI Journal 17(7), 395-403.

Saarikoski, E., Saarinen, T., Salmela, J., and Seppälä, J. (2017). "Erratum to: Flocculated flow of microfibrillated cellulose water suspensions: An imaging approach for characterisation of rheological behaviour," Cellulose 24(12), 5709. DOI: 10.1007/s10570-017-1501-9

Schnell, C. N., Tarrés, Q., Galván, M. V., Mocchiutti, P., Delgado-Aguilar, M., Zanuttini, M. A., and Mutjé, P. (2018). "Polyelectrolyte complexes for assisting the application of lignocellulosic micro/nanofibers in papermaking," Cellulose 25(10), 6083-6092. DOI: 10.1007/s10570-018-1969-y

Sehaqui, H., Zhou, Q., and Berglund, L. A. (2013). "Nanofibrillated cellulose for enhancement of strength in high-density paper structures," Nordic Pulp \& Paper Research Journal 28(2), 182-189. DOI: 10.3183/npprj-2013-28-02-p182-189 
Sehaqui, H., Zhou, Q., Ikkala, O., and Berglund, L. A. (2011). "Strong and tough cellulose nanopaper with high specific surface area and porosity," Biomacromolecules 12(10), 3638-3644. DOI: 10.1021/bm2008907

Siró, I., and Plackett, D. (2010). "Microfibrillated cellulose and new nanocomposite materials: A review," Cellulose 17(3), 459-494. DOI: 10.1007/s10570-010-9405-y

Smook, G. (2016). Handbook for Pulp \& Paper Technologists, M. Kocurek (ed.), TAPPI Press, Atlanta, GA, USA.

Solala, I., Volperts, A., Andersone, A., Dizhbite, T., Mironova-Ulmane, N., Vehniäinen, A., Pere, J., and Vuorinen, T. (2012). "Mechanoradical formation and its effects on birch kraft pulp during the preparation of nanofibrillated cellulose with Masuko refining," Holzforschung 66(4), 477-483. DOI: 10.1515/HF.2011.183

Spence, K. L., Venditti, R. A., Habibi, Y., Rojas, O. J., and Pawlak, J. J. (2010a). "The effect of chemical composition on microfibrillar cellulose films from wood pulps: Mechanical processing and physical properties," Bioresource Technology 101(15), 5961-5968. DOI: 10.1016/j.biortech.2010.02.104

Spence, K. L., Venditti, R. A., Habibi, Y., Rojas, O. J., and Pawlak, J. J. (2010b). "The effect of chemical composition on microfibrillar cellulose films from wood pulps: Water interactions and physical properties for packaging applications," Cellulose 17(4), 835-848. DOI: 10.1007/s10570-010-9424-8

Spence, K. L., Venditti, R. A., Rojas, O. J., Habibi, Y., and Pawlak, J. J. (2011). “A comparative study of energy comsumption and physical properties of microfibrillated cellulose produced by different processing methods," Cellulose 18(4), 1097-1111. DOI: $10.1007 / \mathrm{s} 10570-011-9533-\mathrm{z}$

Stelte, W., and Sanadi, A. R. (2009). "Preparation and characterization of cellulose nanofibers from two commercial hardwood and softwood pulps," Industrial and Engineering Chemistry Research 48(24), 11211-11219. DOI: 10.1021/ie9011672

Su, J., Mosse, W. K. J., Sharman, S., Batchelor, W. J., and Garnier, G. (2013). "Effect of tethered and free microfibrillated cellulose (MFC) on the properties of paper composites," Cellulose 20(4), 1925-1935. DOI: 10.1007/s10570-013-9955-x

Su, J., Zhang, L., Batchelor, W., and Garnier, G. (2014). "Paper engineered with cellulosic additives: Effect of length scale,” Cellulose 21(4), 2901-2911. DOI: 10.1007/s10570-014-0298-z

Sumnicht, D. W. (2012). "Method of making regenerated cellulose microfibers and absorbent products incorporating same," U.S. Patent No. US8177938B2.

Sumnicht, D. W., and Kokko, B. J. (2012). "Absorbent sheet having regenerated cellulose microfiber network," Eur. Patent EP2004904A2.

Sumnicht, D. W., and Miller, J. H. (2016). “Absorbent sheet incorporating regenerated cellulose microfiber,” Eur. Patent. EP2191066A4.

Syverud, K., Chinga-Carrasco, G., Toledo, J., and Toledo, P. G. (2011). "A comparative study of Eucalyptus and Pinus radiata pulp fibres as raw materials for production of cellulose nanofibrils," Carbohydrate Polymers 84(3), 1033-1038. DOI: 10.1016/j.carbpol.2010.12.066

Taipale, T., Österberg, M., Nykänen, A., Ruokolainen, J., and Laine, J. (2010). "Effect of microfibrillated cellulose and fines on the drainage of kraft pulp suspension and paper strength," Cellulose 17(5), 1005-1020. DOI: 10.1007/s10570-010-9431-9

TAPPI WI 3021 (2012). "Proposed new TAPPI standard: Standard terms and their definition for cellulose nanomaterial ( $3^{\text {rd }}$ committee draft)," TAPPI Press, Atlanta, GA, USA. 
Vartiainen, J., Lahtinen, P., Kaljunen, T., Kunnari, V., Peresin, M. S., and Tammelin, T. (2015). "Comparison of properties between cellulose nanofibrils made from banana, sugar beet, hemp, softwood and hardwood pulps," O Papel 76(3), 57-60.

Wijnhoven, P., Dekkers, S., and Hagens, W. I. (2009). "Exposure to nanomaterials in consumer products," RIVM letter report 340370001.

Yousefhashemi, S. M., Khosravani, A., and Yousefi, H. (2019). "Isolation of lignocellulose nanofiber from recycled old corrugated container and its interaction with cationic starch-nanosilica combination to make paperboard," Cellulose 26(12), 7207-7221. DOI: 10.1007/s10570-019-02562-2

Zhao, Y., Moser, C., Lindström, M. E., Henriksson, G., and Li, J. (2017). “Cellulose nanofibers from softwood, hardwood, and tunicate: Preparation-structure-film performance interrelation," ACS Applied Materials and Interfaces 9(15), 1350813519. DOI: $10.1021 /$ acsami.7b01738

Article submitted: August 7, 2019; Peer review completed: December 21, 2019; Revised version received and accepted: February 16, 2020; Published: March 4, 2020.

DOI: 10.15376/biores.15.2.Zambrano 